\title{
Hysteretic Behavior of Specimens of Circular Concrete-Filled CFRP-Steel Tubular Beam-Column
}

\author{
Wang Qing-li, ${ }^{1,2}$ Yu LingFeng, and Peng Kuan iD $^{3}$ \\ ${ }^{1}$ School of Civil Engineering, University of Science and Technology Liaoning, Anshan 114051, China \\ ${ }^{2}$ School of Civil Engineering, Shenyang Jianzhu University, Shenyang 110168, China \\ ${ }^{3}$ School of Mechanical Engineering, Southwest Petroleum University, Chengdu 610500, China \\ Correspondence should be addressed to Peng Kuan; pklut7@163.com
}

Received 15 March 2021; Revised 26 September 2021; Accepted 15 October 2021; Published 19 November 2021

Academic Editor: Suvash Paul

Copyright (C) 2021 Wang Qing-li et al. This is an open access article distributed under the Creative Commons Attribution License, which permits unrestricted use, distribution, and reproduction in any medium, provided the original work is properly cited.

\begin{abstract}
To study the difference in hysteretic behavior of specimens of circular concrete-filled CFRP-steel tube under different influencing factors, 12 specimens were designed, and their failure modes and $P-\Delta$ curves were studied. ABAQUS was used to simulate the specimens' $P-\Delta$ curves and deformation mode. Based upon the simulation results, the stress distribution of all of the specimens' component materials and the interaction between the steel tube and concrete was analyzed throughout the entire loading process, and the trilinear model, the restoring force model of circular concrete-filled CFRP-steel tube, was proposed. All of the specimens' $P-\Delta$ curves were full and demonstrated excellent hysteretic behavior. The specimens' $P-\Delta$ curves, the skeleton curves, and deformation mode were simulated by the ABAQUS, and the simulation results agreed well with the experimental results. Further, the results of the restoring force model built based upon the trilinear model agreed well with the finite element simulation results.
\end{abstract}

\section{Introduction}

In recent years, earthquakes are more and more widespread in the world. The distribution of seismic zones is not uniform, but they are widely distributed. Some scholars have carried out extensive and in-depth research on the seismic design of building structures, and the earthquakes have caused huge economic losses and casualties. To deal with the threat of earthquake disaster to buildings, the research on hysteretic behavior of building structures is more and more extensive. Nowadays, the most commonly used composite structure is steel-concrete composite structure. It is a composite structure composed of steel and concrete, which mainly uses the advantages of compressive performance of concrete and tensile performance of steel. Not only is this composite structure convenient for construction, but it also saves a lot of materials, so as to achieve the goals of reducing the cost, reducing the weight of components, and shortening the construction period. Therefore, the steel-concrete composite structure is widely used in practical engineering.
Liu and Dong [1] carried out the torsion tests of 16 circular CFRP concrete-filled steel tubes. The results show that the failure modes of the specimens bonded with longitudinal CFRP and circumferential CFRP are different. Romero et al. [2] carried out experimental research and finite element theoretical analysis on fire performance of concrete-filled steel tubular members. The results show that the steel tube and CFRP can work together, and the deformation of the component approximately conforms to the plane section assumption. Han and Zhong [3] deduced the axial force torque correlation equation of concrete-filled steel tubular members, described the moment torque correlation equation, and analyzed the whole process of such specimens. Nie et al. [4] conducted an experimental study on the torsional hysteretic behavior of concrete-filled steel tubes with circular section and rectangular section. The results show that the hysteretic curve is very full, and the unloading stiffness and the initial loading stiffness of the specimen are almost the same, and the specimen shows good energy dissipation performance; the torsion resistance of the 
specimen with too large axial compression ratio is weakened due to too serious deformation. Zhou et al. [5] carried out the pure torsional hysteretic behavior test of hollow sandwich concrete-filled steel tubular specimens with section form and void ratio as the main parameters. The experimental results show that the initial elastic stiffness is close to the unloading stiffness, and the specimens show good energy dissipation capacity [6], and the hysteretic behavior of circular section hollow sandwich concrete-filled steel tube is better than that of square section $[7,8]$. Sundarraja and Prabhu [9] found that the steel ratio and the number of CFRP layers have great influence on the bearing capacity of square CFRP-CFST specimens and proposed a finite element simulation method to reproduce the mechanical behavior of square CFRP-CFST effectively. Tao et al. $[10,11]$ indicated that the bearing capacity of CFRP-CFST specimens was significantly reduced after fire, but the fire resistance ability of concrete-filled CFRP-steel tube specimens was better than that of ordinary concrete-filled steel tube specimens. Peng et al. [12] studied the influence of various materials on the bearing capacity of square concrete-filled CFRP-steel tube under axial compression. Wang et al. [13] and Che et al. [14] studied the influence of slenderness ratio and eccentric ratio on the performance of square concrete-filled CFRP-steel tube. At present, most of the researches are focused on the static performance of components. Therefore, it is necessary to study the CFRP-CFST under hysteretic load and establish a more accurate restoring force model.

In view of this, 12 groups of circular CFRP concretefilled steel tube specimens were designed in experiment. Referring to the hysteretic test of concrete-filled steel tube, the specimens' failure modes and the lateral force-deflection $P-\Delta$ curve were studied. The specimens' $P-\Delta$ curve and deformation mode were simulated with ABAQUS. On this basis, each component material's stress distribution and the interaction between the steel tube and concrete were analyzed. Based upon the trilinear model, the restoring force model of C-CF-CFRP-ST was proposed. Finally, the model's calculation results were compared with the results of finite element simulation to verify the model's accuracy.

\section{Performance of Raw Materials and Test Design}

\subsection{Performance of Raw Material}

2.1.1. Steel. Longitudinal welded steel tube was used. The material properties of the steel are shown in Table $1 . f_{\mathrm{y}}$ is the yield strength of steel tube. $f_{\mathrm{u}}$ is the ultimate strength of steel tube. $E_{\mathrm{s}}$ is the elastic modulus of steel tube. $\varepsilon_{\mathrm{sy}}$ is the yield strain of steel tube. $v_{s}$ is Poisson's ratio, and $\varepsilon$ ' is the elongation of steel.

2.1.2. Concrete. Portland cement with a strength grade of 42.5 was used in the experiment. Medium coarse sand was used as fine aggregate. The particle size of the coarse aggregate gravel was $5 \sim 15 \mathrm{~mm}$, and a water reducer with $1 \%$ cement weight was added. The specific ratio of the concrete
TABLE 1: The material properties of steel tube used in experiment.

\begin{tabular}{lcccccc}
\hline Section & $f_{\mathrm{y}}(\mathrm{MPa})$ & $f_{\mathrm{u}}(\mathrm{MPa})$ & $E_{\mathrm{s}}(\mathrm{GPa})$ & $\varepsilon_{\text {sy }}(\mu \varepsilon)$ & $v_{s}$ & $\varepsilon^{\prime}(\%)$ \\
\hline Circular & 298 & 425 & 199 & 2502 & 0.28 & 27 \\
\hline
\end{tabular}

is shown in Table 2. The concrete mix used in this experiment refers to the C50 concrete which is prepared according to the European concrete code and Chinese concrete code.

After 28 days of standard curing, the concrete cube's compressive strength $\left(f_{\mathrm{cu}}\right)$ was $47.8 \mathrm{MPa}$ and the elastic modulus $\left(E_{\mathrm{c}}\right)$ was $34.6 \mathrm{GPa}$. The cube's compressive strength was $77.7 \mathrm{MPa}$ during the hysteretic test.

2.1.3. CFRP and Viscose. Carbon fiber fabric is a unidirectional fabric woven with carbon fiber made in China. Its main properties are shown in Table 3.

The adhesive and base adhesive are building structural adhesives produced by China Institute of Construction Science and Technology in the test.

Firstly, concrete-filled steel tube was prepared according to Han et al. [15]. After that, acetone was used to clean the welding slag and oil on the steel tube surface. The viscose was evenly applied on the surface of steel tube, and part of the viscose was evenly applied on the surface of CFRP. The bubbles were removed by scraping to ensure that the adhesive completely penetrated into CFRP. The sequence of pasting CFRP is as follows: paste the longitudinal CFRP firstly. When its surface is dry, then paste the transverse CFRP, and lap length of transverse CFRP is $150 \mathrm{~mm}$. Finally, apply a layer of adhesive on the outer layer to make it completely cured within one week.

2.2. Test Design. A total of 12 specimens were designed, and the hysteretic behavior of the specimens was tested. The main parameters include axial compression ratio $(n)$ and longitudinal CFRP reinforcement coefficient $(\eta)$ :

$$
n=N_{0} / N_{u, c r},
$$

where $N_{0}$ is the axial force applied to the specimen.

The calculated length $(L)$ of each group is $2000 \mathrm{~mm}$, the outer diameter $\left(D_{\mathrm{s}}\right)$ is $140 \mathrm{~mm}$, the wall thickness $\left(t_{\mathrm{s}}\right)$ is $4 \mathrm{~mm}$, and the number of transverse CFRP layers $\left(m_{\mathrm{t}}\right)$ is 1 , where $n$ is the axial compression ratio, $\eta$ is the longitudinal CFRP reinforcement coefficient, $m_{1}$ is the number of longitudinal CFRP layers, $\Delta_{\mathrm{y}}$ is the yield displacement of the specimen, and the specific parameters of each specimen are shown in Table 4.

Before the test, the specimens are placed horizontally and hinged at both ends. The axial force is applied by the electrohydraulic servo system actuator set horizontally, and the hysteretic force is applied by the electrohydraulic servo system actuator set vertically in the middle section. The actuator is connected with the test piece through a rigid fixture. In order to avoid out-of-plane instability of the specimen during loading, a set of lateral support devices are designed, which are respectively set at two quarter points of the specimen. The loading panorama of specimens with 
TABle 2: Specific ratio of concrete $\mathrm{kg} / \mathrm{m}^{3}$.

\begin{tabular}{lccc}
\hline Cement & Water & Fine aggregate & Coarse aggregate \\
\hline 490 & 171.5 & 661.5 & 1078 \\
\hline
\end{tabular}

TABLE 3: Basic performance parameters of CFRP.

Thickness of single layer $(\mathrm{mm})$ Weight $\left(\mathrm{g} / \mathrm{m}^{3}\right)$ Elongation at break (\%) Tensile strength of monofilament (GPa) Elastic modulus (GPa) $\begin{array}{lllll}0.111 & 200 & 2.1 & 4.9 & 230\end{array}$

TABle 4: Parameters of C-CF-CFRP-ST specimens.

\begin{tabular}{lcccccc}
\hline Order & Number & $n$ & $m_{1}$ (layers) & $\eta h$ & $N_{0}(\mathrm{kN})$ & $D_{\mathrm{y}}(\mathrm{mm})$ \\
\hline 1 & A0 & 0 & 0 & 0 & 0 & 12.1 \\
2 & A1 & 0 & 1 & 0.157 & 0 & 13.1 \\
3 & A2 & 0 & 2 & 0.314 & 0 & 13.1 \\
4 & B0 & 0.2 & 0 & 0 & 228 & 13.1 \\
5 & B1 & 0.2 & 1 & 0.157 & 230 & 12.1 \\
6 & B2 & 0.2 & 2 & 0.314 & 233 & 12.1 \\
7 & C0 & 0.4 & 0 & 0 & 455 & 11.3 \\
8 & C1 & 0.4 & 1 & 0.157 & 460 & 9.3 \\
9 & C2 & 0.4 & 2 & 0.314 & 466 & 8.6 \\
10 & D0 & 0.6 & 0 & 0 & 681 & 11.1 \\
11 & D1 & 0.6 & 1 & 0.157 & 691 & 10.1 \\
12 & D2 & 0.6 & 2 & 0.314 & 698 & 6.6 \\
\hline
\end{tabular}

compression bending hysteretic behavior is shown in Figure 1.

The load-displacement control method was used in the test. The actual load is constant, and lateral load is cyclic in this test. Both the lateral load and the axial load are loaded by actuators, and the direction has been shown in Figure 2. Section diagram of C-CF-CFRP-ST specimens is shown in Figure 3. At the initial stage of the test, the load was controlled and loaded in stages, respectively, according to $0.25 P_{u c}\left(P_{u c}\right.$ is the estimated lateral bearing capacity), $0.5 P_{u c}$, and $0.7 P_{u c}$, and each stage load cycle was 2 times; after that, the displacement was controlled and loaded in stages, according to $1.0 \Delta_{y}, 1.5 \Delta_{y}, 2.0 \Delta_{y}$, $3.0 \Delta_{y} 5.0 \Delta_{y}, 7.0 \Delta_{y}$, and $8.0 \Delta_{y}, \Delta_{y}=P_{u c} / \mathrm{K}_{0.7}$, and the secant stiffness of $P-\Delta$ skeleton curve when $\mathrm{K}_{0.7}$ is $0.7 P_{u c}$. The load cycle of other stages is twice. Before the test, the axial force of $0.5 N_{0}$ is used to load and unload once, so as to reduce the influence of the internal structure inhomogeneity [16-18].

During the test, the INV-306D intelligent signal acquisition and analysis system connected with the vertical actuator of the electrohydraulic servo system directly collects $P$ and $\Delta$. The INV-306D intelligent signal acquisition and analysis system connected with the horizontal actuator of the electrohydraulic servo system directly collects $N_{0}$ and $\Delta^{\prime}$. The deflection is measured with a displacement meter at two quarter points close to the two supports. One transverse strain gauge and one longitudinal strain gauge are, respectively, pasted on the steel tube and CFRP tube at the outermost edge of the middle section and the lower section to measure the strain. Loading system of C-CF-CFRP-ST specimens is shown in Figure 4 .

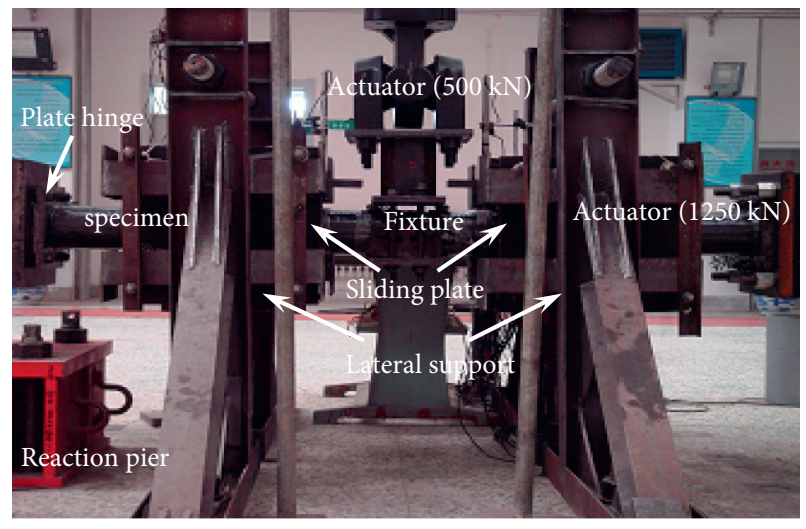

FIGURE 1: Loading equipment of hysteretic performance test of specimens.

\section{Test Results and Analysis}

3.1. Test Phenomenon. Before reaching the yield-loading, the $P-\Delta$ curve of the specimen is basically linear, and there is no obvious residual deformation. With the increase of the lateral displacement, there is a small bulge at the connection between the rigid fixture and the specimen. After that, the axial compression ratio has a significant effect on the experimental phenomena.

For the specimen with small axial compression ratio ( $n \leq 0.2$ ), when loading to $3 \Delta_{\mathrm{y}} \sim 5 \Delta_{\mathrm{y}}$, the microbulge occurs on both sides of the fixture. With unloading and reverse loading, the bulge is flattened again, and causes the microbulge in the compression area on the other side. When loading to $5 \Delta_{\mathrm{y}}$, for the specimens with longitudinal CFRP, it can be found that the transverse CFRP fibers cracked, and the longitudinal CFRP began to break sporadically. When loading to $7 \Delta_{y}$, the drumming began to develop significantly, and a continuous burst sound was emitted. At this time, the transverse CFRP is slightly fracture, and the longitudinal CFRP begins to fracture in large stage. As shown in Figure 5(a), A1 specimen has both transverse and longitudinal CFRP, naked leakage appears on the outer wall of the steel tube, which indicates that the longitudinal CFRP is fractured a lot. After that, the transverse CFRP begins to fracture in a large scale. For the specimens without longitudinal CFRP, as shown in Figure 5(b), only when the deflection is large at the later stage of loading, a large number of transverse CFRP fractures begin to appear.

As shown in Figure 6(a), for the specimen with large axial compression ratio $(n \geq 0.4)$, the change of the specimen is basically consistent with that of the specimen with small 




FIGURE 2: Loading diagram of C-CF-CFRP-ST specimens with compression bending hysteretic behavior.

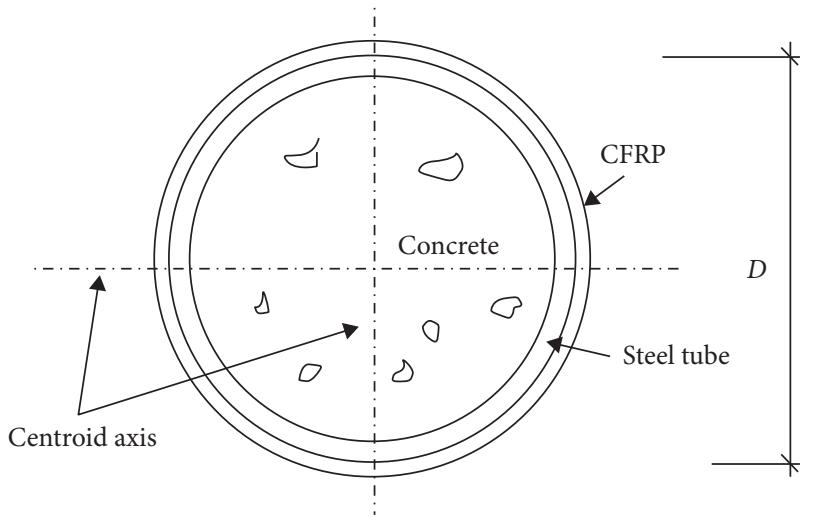

FIGURE 3: Section diagram of C-CF-CFRP-ST specimens.

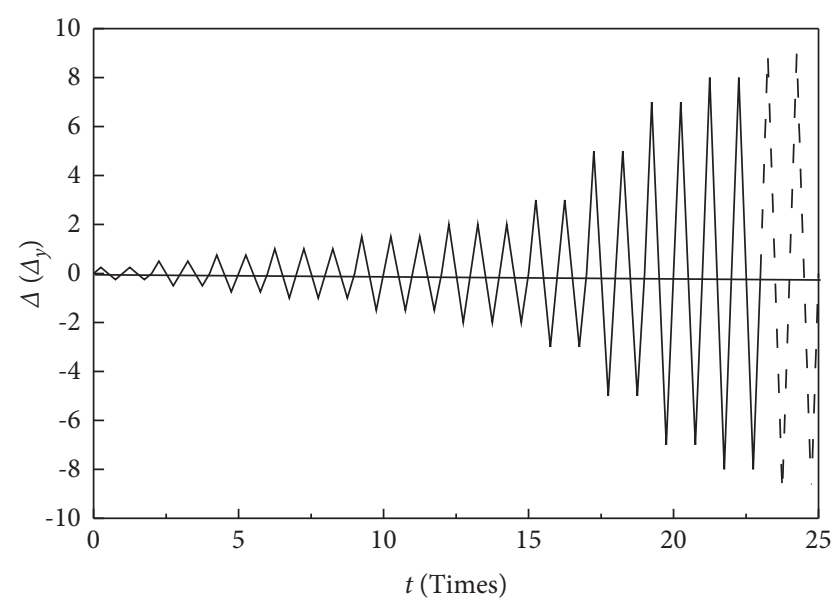

Figure 4: Loading system of C-CF-CFRP-ST specimens.

axial compression ratio $(n \leq 0.2)$ when the load is $3 \Delta_{\mathrm{y}} \sim 5 \Delta_{\mathrm{y}}$. After loading to $7 \Delta_{\mathrm{y}}$, the transverse and longitudinal CFRP of specimens begin to fracture gradually. For specimens without longitudinal CFRP, the transverse CFRP begins to fracture gradually, as shown in Figure 6(b).

Based on this, it can be found that with the increase of $\eta$ the damage degree of the specimen is reduced. Figure 7 shows all the specimens with circular section after loading.
After the loading specimen is broke, it can be seen that there are some tiny bulges in the interior of the specimen, as shown in Figure 8(a), and there are fewer cracks in the corresponding position of the concrete, as shown in Figure 8(b), which indicates that the concrete confined by CFRP and steel tube has good plastic filling performance, and the test performance is that the failure characteristics of the specimen are not obvious.

\subsection{The Curve of $P-\triangle$}

3.2.1. The Hysteresis Curve of $P-\Delta$. Figure 9 shows the $P-\Delta$ curve of the specimen. It can be seen that the hysteretic curve of the specimen is full and there is no pinch phenomenon. In the initial stage of loading, the specimen is basically in the elastic stage, and the hysteretic curve changes approximately linearly. After yielding, the residual deformation gradually increases, and the stiffness decreases. From unloading to reverse loading, the stiffness of the specimen changes little. For the specimen without axial compression ratio, the bearing capacity does not decrease in the later stage of loading. For the specimen with axial compression ratio, the bearing capacity decreases in the later stage of loading obviously. The specimen without axial compression ratio only bears the action of bending moment and consumes less energy. Compared with the specimen with axial compression ratio, its bearing capacity is not reduced. In addition, with the increase of axial compression ratio, the compression area of core concrete increases, which is more likely to lead to concrete cracking and reduce the later bearing capacity of specimens [3].

3.2.2. $P-\Delta$ Skeleton Curve. Figure 10 shows the $P-\Delta$ skeleton curves of specimens with different axial compression ratios. Figure 11 shows the local section $P-\Delta$ skeleton curves. It can be seen that, with the increase of axial compression ratio, the lateral bearing capacity and elastic stiffness of the specimen decrease. However, the curve of the circular specimen with $\eta=0$ has no decreasing stage. When $\eta>0$, the curve of the specimen has decreasing stage, and the descending range increases with the improvement of the axial compression ratio. 


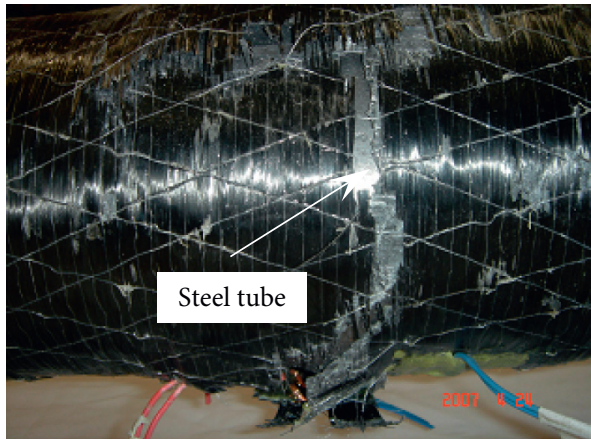

(a)

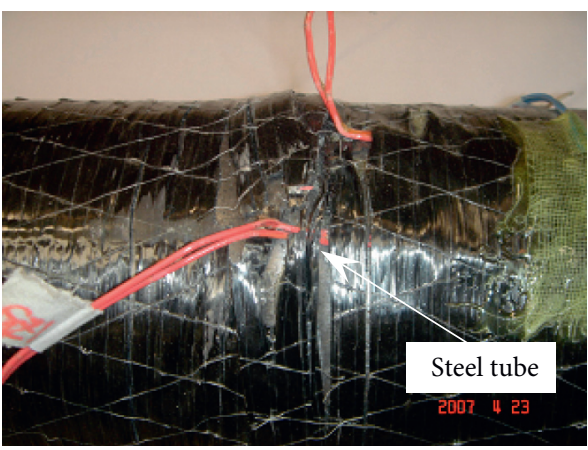

(b)

FIGURE 5: Fracture of CFRP of specimens with a small axial compression ratio. (a) Longitudinal CFRP of A1. (b) Transverse CFRP of A0.

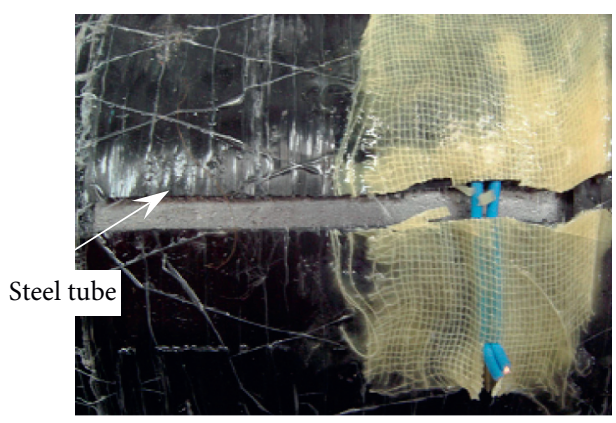

(a)



(b)

FIgURE 6: Fracture of CFRP of specimens with a large axial compression ratio. (a) Longitudinal CFRP of C1. (b) Transverse CFRP of C0.

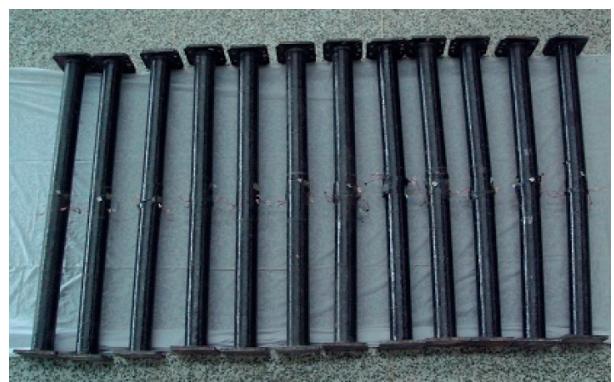

Figure 7: The C-CF-CFRP-ST specimens after loading.

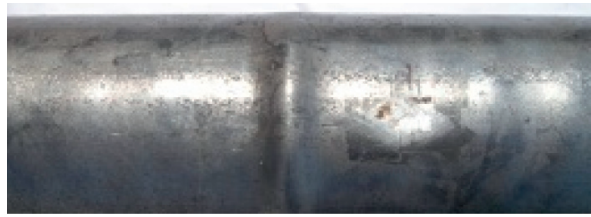

(a)

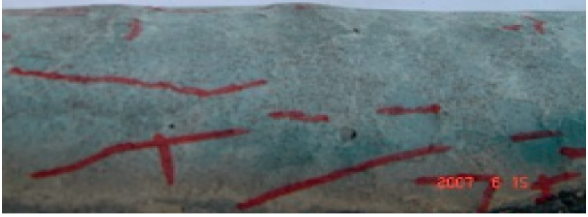

(b)

FIGURE 8: Internal and external damage of specimen failure. (a) Steel tube. (b) Concrete.

\section{Finite Element Simulation}

4.1. Element Type Selection and Mesh Discretization. The adopted element in the mesh of the steel tube is shell element S4 with full integration. Simpson integration with 9 integrating points in the shell thickness direction is used. For the mesh of the concrete, 3D brick element C3D8R with reduced integration is used. Membrane element M3D4 with 4nodes is used for modelling CFRP $[19,20]$. 




(a)

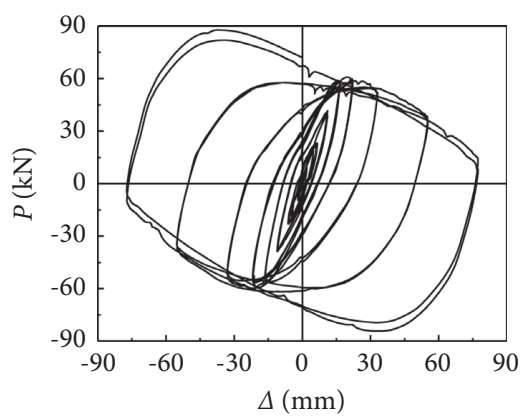

(d)

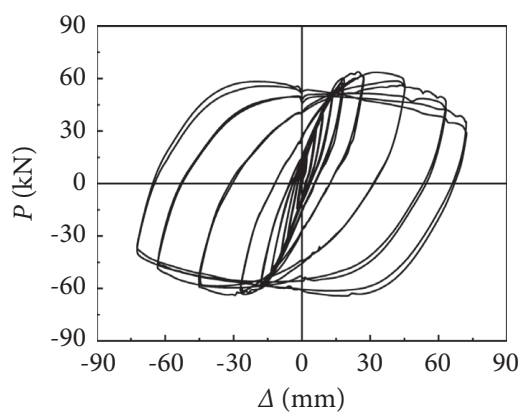

(g)

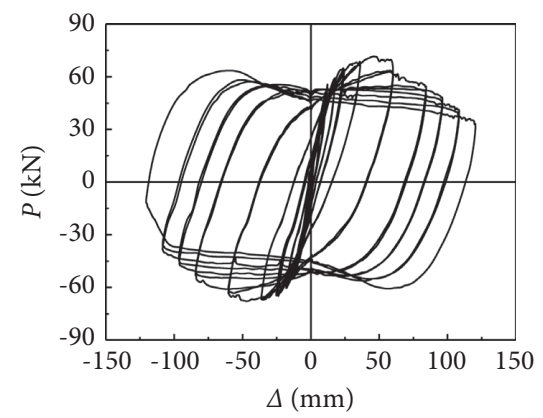

(j)

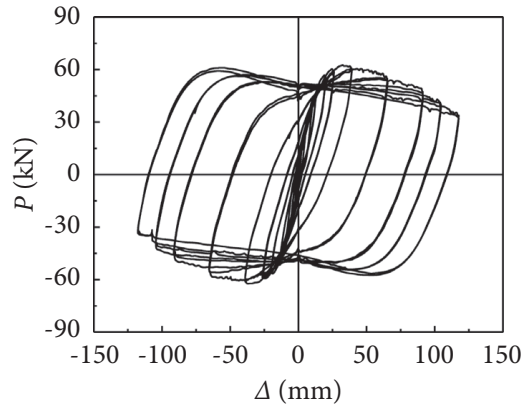

(b)

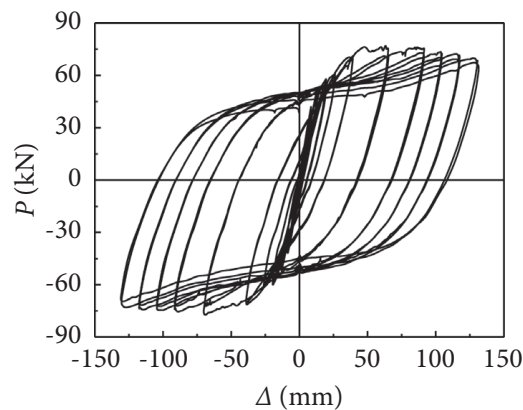

(e)

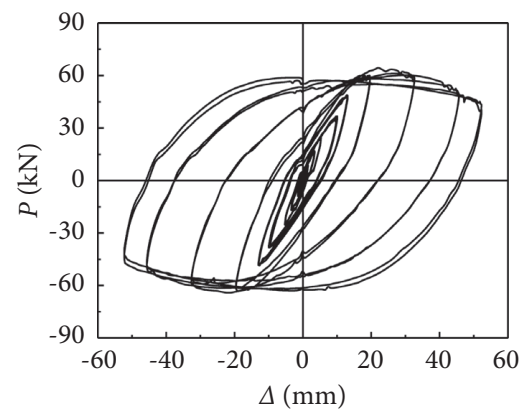

(h)

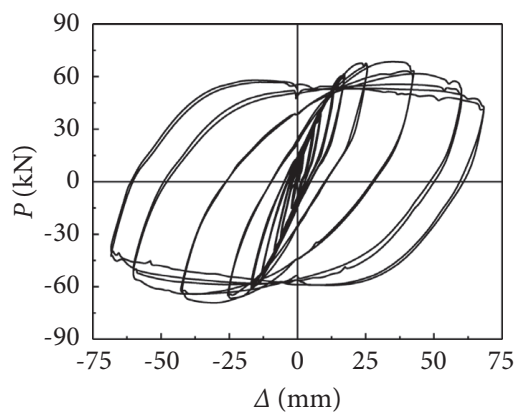

(k)

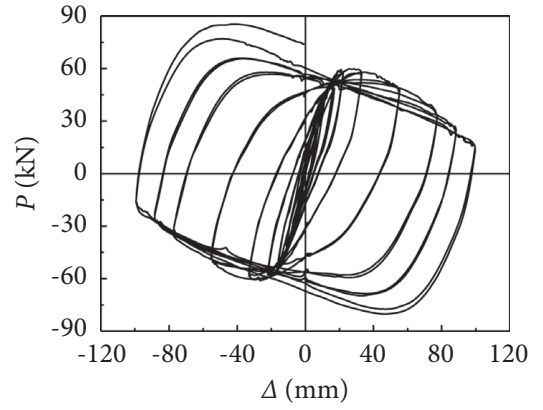

(c)



(f)



(i)

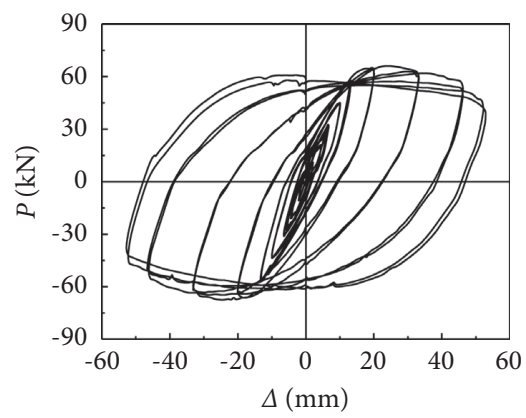

(1)

Figure 9: $P$ - $\Delta$ curves of specimens. (a) A0 specimen. (b) B0 specimen. (c) C0 specimen. (d) D0 specimen. (e) A1 specimen. (f) B1 specimen. (g) C1 specimen. (h) D1 specimen. (i) A2 specimen. (j) B2 specimen. (k) C2 specimen. (l) D2 specimen.

4.2. Stress-Strain Relationship of Materials. The details of the stress-strain relationships of the steel are determined according to the constitutive model suggested by Han and
Zhong [3]. The Concrete Damage Plasticity is used in the finite element simulation of concrete, and stress-strain of concrete relationship is shown in the following equation: 




(a)

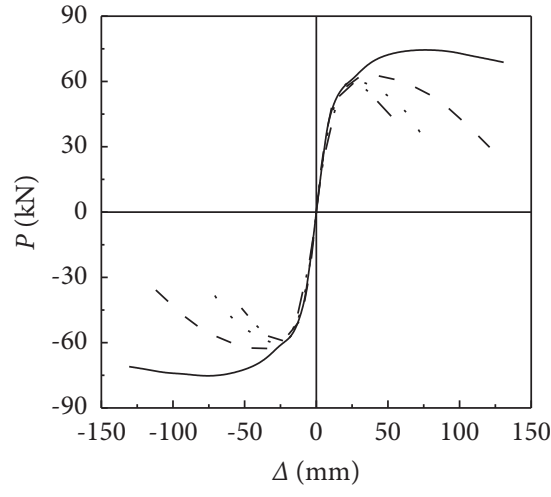

$-\mathrm{A} 1$

….. $\mathrm{C}$

... D1

(b)

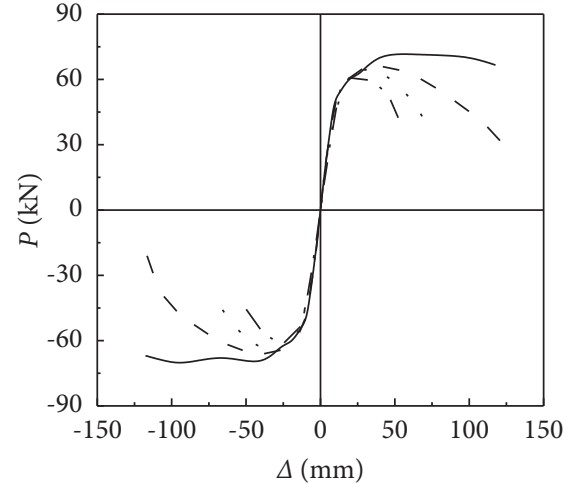

- A2

..... $\mathrm{C} 2$

(c)

Figure 10: Effect of axial compression ratio on $P-\Delta$ skeleton curve of specimens. (a) $\eta=0$ specimens. (b) $\eta=0.157$ specimens. (c) $\eta=0.314$ specimens.

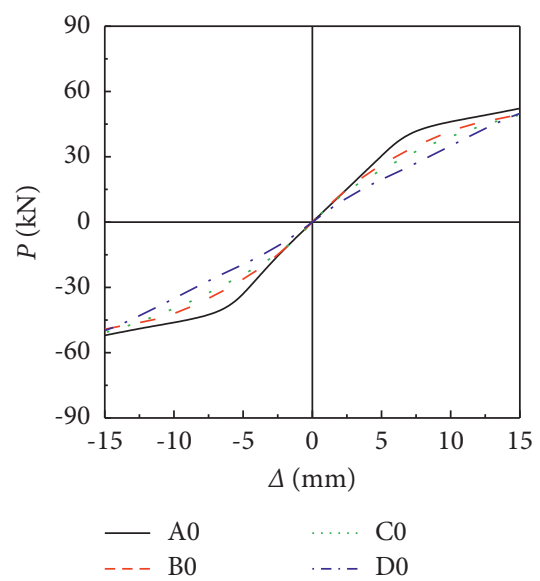

(a)



$-\mathrm{A} 1$

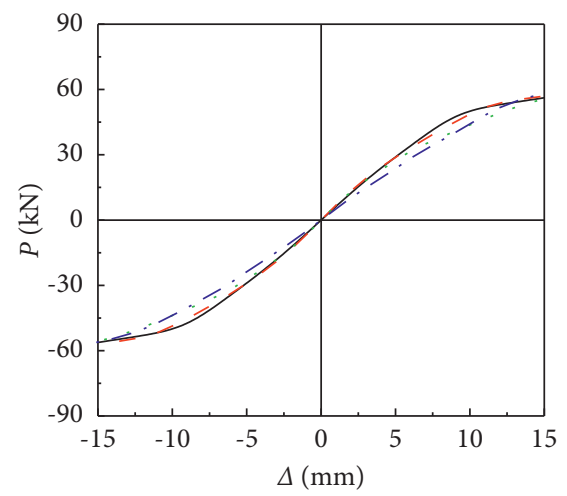

$\begin{array}{rrr}\mathrm{A} 2 & \cdots \mathrm{C} 2 \\ --\mathrm{B} 2 & - & -\mathrm{D} 2\end{array}$

(c)

Figure 11: The local section on $P-\Delta$ skeleton curve of specimens. (a) $\eta=0$ specimens. (b) $\eta=0.157$ specimens. (c) $\eta=0.314$ specimens.

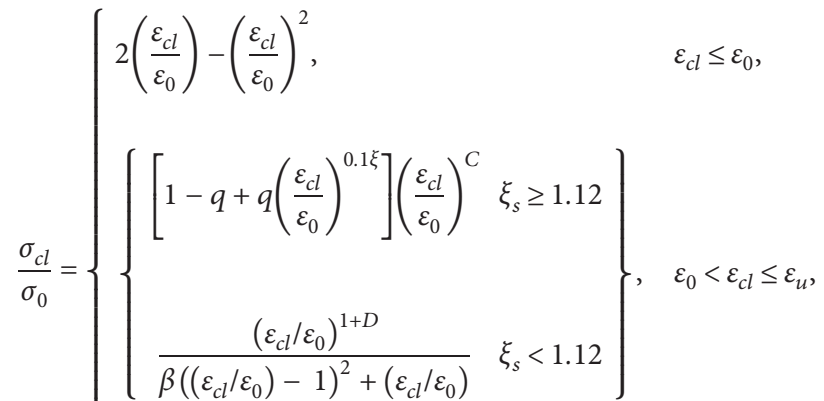

$$
\begin{aligned}
& \frac{\varepsilon_{c l} / \varepsilon_{0}}{\beta_{s}\left(\left(\varepsilon_{c l} / \varepsilon_{0}\right)-1\right)^{2}+\left(\varepsilon_{c l} / \varepsilon_{0}\right)}, \quad \quad \varepsilon_{c l}>\varepsilon_{u},
\end{aligned}
$$

$\sigma_{0}=f_{c}^{\prime}(\mathrm{MPa})$

$$
\begin{gathered}
\varepsilon_{0}=\varepsilon_{c c}+\left(600+32.4 f_{c}^{\prime}\right) \xi^{0.2} \times 10^{-6}, \\
\varepsilon_{c c}=\left(1300+12.09 f_{c}^{\prime}\right) \times 10^{6}, \\
q=\frac{\xi^{0.745}}{(2+\xi)}, \\
C=\zeta(2.231-4.611 \zeta \prime), \\
D=\zeta_{\prime}(1.545-1.238 \zeta \prime),
\end{gathered}
$$

$$
\beta=3.28\left(2.36 \times 10^{-5}\right)^{0.25+(\xi-0.5)^{7}} f_{c}^{\prime 2} \times 10^{-4}
$$$$
\beta_{s}=0.5\left(2.36 \times 10^{-5}\right)^{0.25+\left(\xi_{s}-0.5\right)^{7}} f_{c}^{\prime 2} \times 10^{-4},
$$ 


$$
\varepsilon_{u}=\varepsilon_{0}+51659 \xi_{\mathrm{cf}}-38904 \xi_{\mathrm{cf}}^{2},
$$

where compressive strength of the concrete is defined as $f^{\prime} c$. $\xi^{\prime}$ is confinement factor ratio. $q, C$, and $D$ are related parameters about $\xi$. $\beta$ and $\beta_{\mathrm{s}}$ are related parameters about $\xi_{\mathrm{s}} \cdot \varepsilon_{u}$ is the longitudinal strain of the specimen. The failure energy criterion of concrete is used to simulate the tension of concrete.

$$
\begin{aligned}
& G_{f}=40+4\left(f_{c}^{\prime}-20\right), \\
& \sigma_{t 0}=0.26\left(1.5 f_{c}^{\prime}\right)^{2 / 3},
\end{aligned}
$$

where total energy consumed in concrete fracture process is defined as $G_{f}$ and $\sigma_{t 0}$ is the ultimate tensile strength of concrete.

The shrinkage and the creep are not considered for concrete material in the finite element model.

The confinement of transverse CFRP is quantified by the confinement factor of transverse CFRP $\left(\xi_{\mathrm{cf}}\right)$ proposed. The reinforcement efficiency of longitudinal CFRP is defined as a strengthening coefficient $(\eta)$. All influence factors are given from (15) to (17).

$$
\begin{aligned}
\eta & =\frac{A_{\mathrm{cfl}} f_{\mathrm{cfl}}}{\left(A_{s} f_{y}\right)}, \\
A_{\mathrm{cft}} & =E_{\mathrm{cf}} \varepsilon_{\mathrm{cftr}}, \\
f_{\mathrm{cfl}} & =E_{\mathrm{cf}} \varepsilon_{\mathrm{cflr}},
\end{aligned}
$$

where $A_{\text {cft }}$ and $f_{\text {cft }}$ are the cross-sectional area and the ultimate tensile strength of the transverse CFRP, respectively. $A_{\mathrm{cfl}}$ and $f_{\mathrm{cfl}}$ are the cross-sectional area and the ultimate tensile strength of the longitudinal CFRP, respectively. It has been verified by previous experiments that lateral restraint of CFRPs to the steel tube is lost once the fracture strain of transversal CFRP is reached $\left(\varepsilon_{\mathrm{cftr}}=5500 \mu \varepsilon\right)$. When the rupture strain of longitudinal CFRPs is reached $\left(\varepsilon_{\mathrm{cflr}}=10000 \mu \varepsilon\right)$, the longitudinal strengthening effect to the members is lost $[21,22]$.

4.3. Division of Mesh, Interactions, and Boundary Condition. The refined mesh method is used to analyze the mesh convergence before meshing. Because the pressure between steel tube and concrete can only be transferred on the surfaces of two materials, the hard contact mode is adopted between them. It is assumed that the steel tube and the end plate are integral part in the finite element model, so the element nodes of the steel tube and the end plate on the contact surface have the same nodal degree of freedom. In the finite element simulation, there is no slip in the tangential direction, and it is hard contact between the end plate and the concrete in the normal direction. CFRP and steel tube contact adopts bonding. Figure 12 shows the boundary conditions for the finite element simulation of specimens.

Firstly, half of the whole component was selected, and then quarter of the specimen was cut. According to the symmetry of the geometry and boundary conditions of the component, the quarter model of the actual component is taken for analysis, and the symmetrical constraint conditions are imposed on the symmetry plane of the calculation model. The boundary condition is that the surface load is applied on the end plate and the lateral hysteretic force is applied on the middle section. In order to ensure that the loading mode is consistent with that in the test process, the loading-displacement control mode is adopted.

\subsection{Comparison of Finite Element Simulation and Test Results.} Figures 13 and 14 show the comparison between the simulation results and the test results of $P-\Delta$ curve and $P-\Delta$ skeleton curve of partially C-CF-CFRP-ST specimens, respectively. Figures 15(a) and 15(b) show the actual failure modes and the finite element simulation failure modes of the steel tube in the specimens, respectively. Figures 16(a) and 16(b) show the failure modes of concrete in specimens and those of finite element simulation, respectively. It can be seen that the simulation results are in good agreement with the experimental results. The test results of each group are basically consistent with the finite element simulation results, which shows that the simulation results of the established model are in good agreement with the actual test results. Table 5 shows comparative error analysis of test and finite element skeleton curves. The elastic stiffness and ultimate bearing capacity of the test and finite element models are calculated, respectively. The calculation results show that the error between test and finite element is less than $20 \%$. The mean square deviation of elastic stiffness and ultimate bearing capacity between test and finite element is calculated. The mean square deviation of elastic stiffness between test and finite element is 0.89 , and the mean square deviation of the ultimate bearing capacity between test and finite element is 0.84 . This shows that the finite element model is in good agreement with the experimental results.

\section{Analysis of the Entire Load Process}

Figure 17 shows the specimens' typical $P-\Delta$ curve. Six characteristic points were selected in the curve. Point $\mathrm{O}$ corresponds to the completed state of axial compression $\left(N_{0}\right)$. A corresponds to the steel tube's yielding state. B corresponds to the fractured state of longitudinal CFRP, and C corresponds to the fractured state of transverse CFRP. Point $D$ corresponds to the state of load reach bearing capacity, and $E$ corresponds to the state of deflection $(\Delta)$ reached at $7 \Delta_{y}$, when deflection is approximately $L / 25$.

5.1. Distribution of the Interaction between Steel Tube and Concrete. Figure 18 shows the distribution of the interaction between C-CF-CFRP-ST specimens' concrete and steel tubes during loading from point $O$ to point $E$. It can be seen that the interaction between the tube and concrete was reflected primarily in the compression zone.

At point $O$, the interaction between steel tube and concrete is small because Poisson's ratio of steel tube is larger than that of concrete, and the transverse deformation of concrete is smaller than that of steel tube. With the yield 


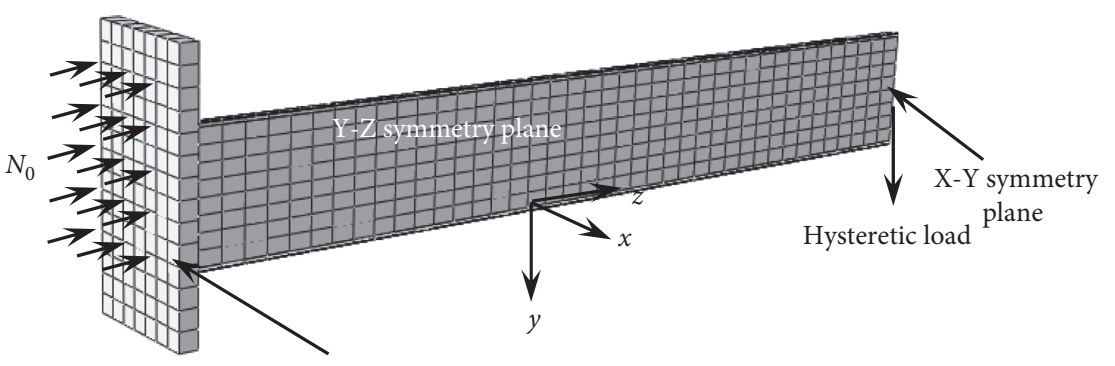

Constraint point of displacement and rotation

FIGURE 12: Boundary conditions for the specimens' finite element simulation.

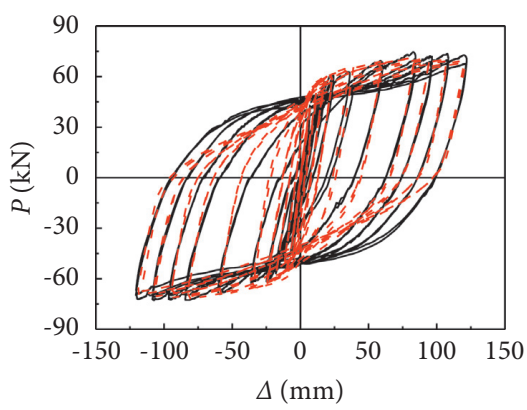

- Test Result

- - - FE Result

(a)

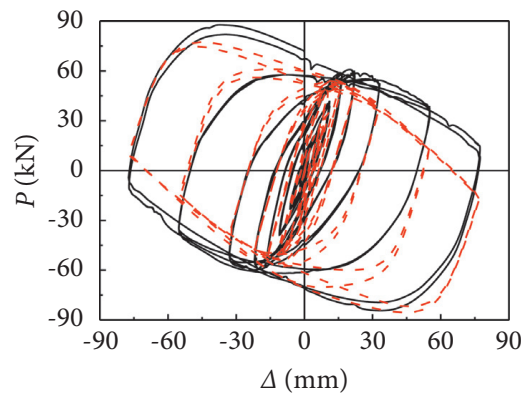

— Test Result

- - - FE Result

(d)

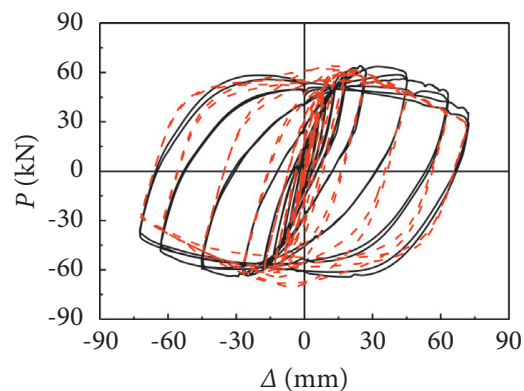

— Test Result

- - FE Result

(g)

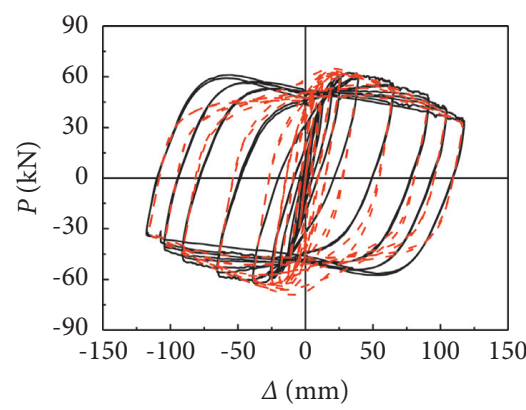

- Test Result

- - FE Result

(b)



— Test Result

- . - FE Result

(e)

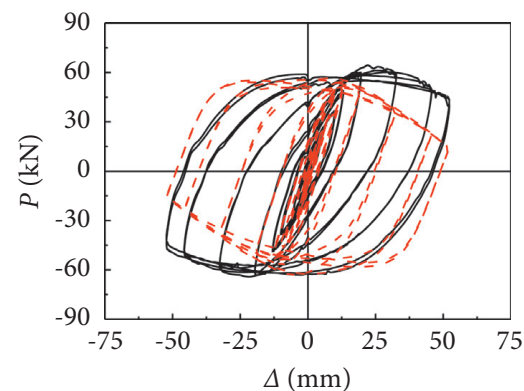

— Test Result

- - - FE Result

(h)

Figure 13: Continued.

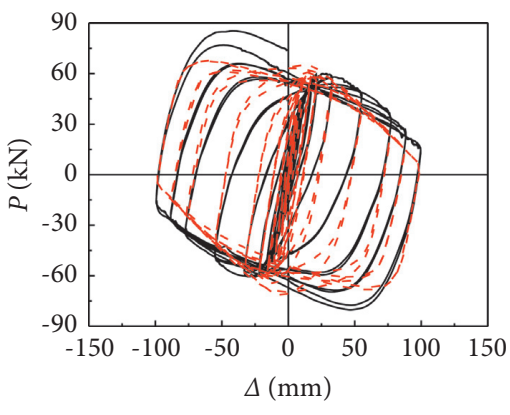

- Test Result

- - FE Result

(c)

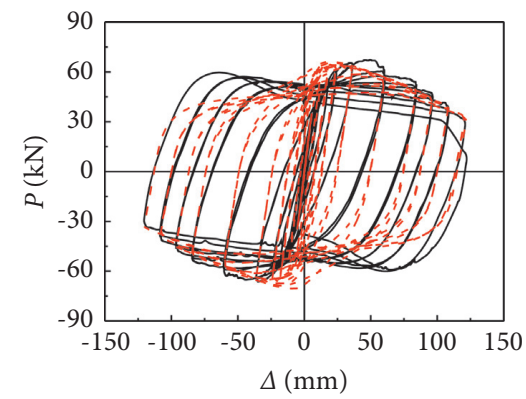

— Test Result

- - - FE Result

(f)

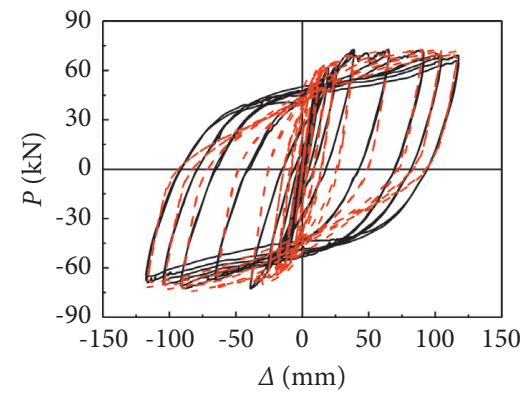

— Test Result

- - - FE Result

(i) 




- Test Result - - - FE Result

(j)

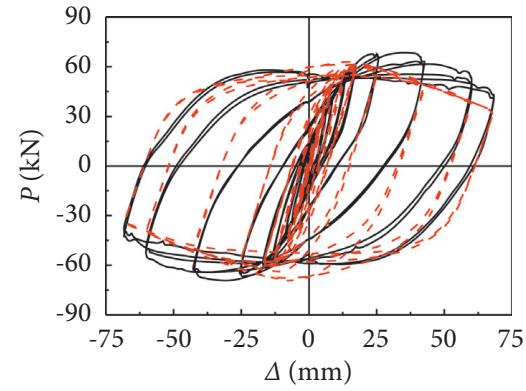

— Test Result

- - - FE Result

(k)



- Test Result

- - - FE Result

(l)

FIgURE 13: Comparison of simulation results and experimental results of $P-\Delta$ curves of specimens. (a) A0 specimen. (b) B0 specimen. (c) C0 specimen. (d) D0 specimen. (e) A1 specimen. (f) B1 specimen. (g) C1 specimen. (h) D1 specimen. (i) A2 specimen. (j) B2 specimen. (k) C2 specimen. (l) D2 specimen.

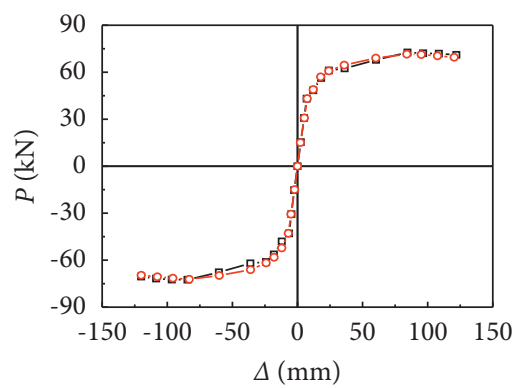

- - - Test Result

-o- FE Result

(a)

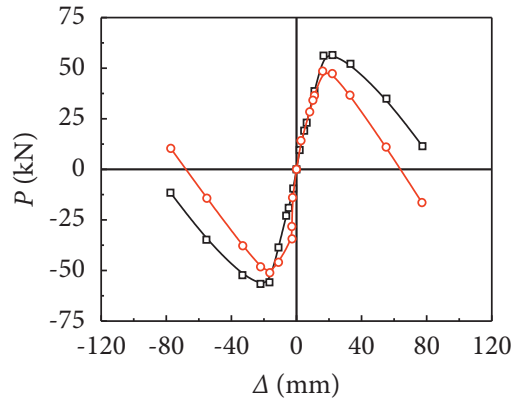

- - Test Result

-०- FE Result

(d)

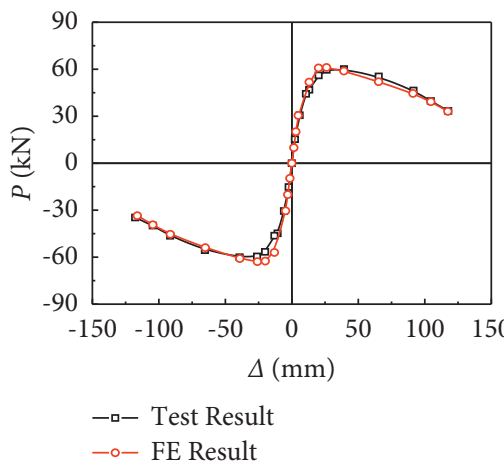

(b)

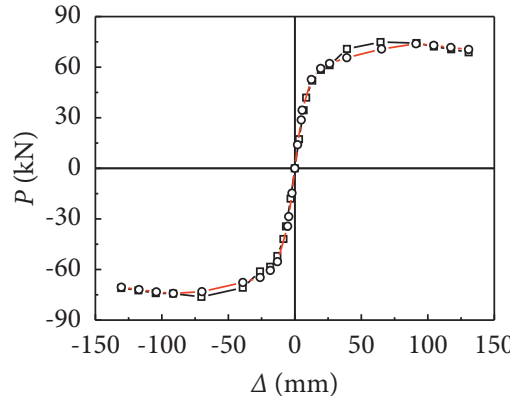

- - Test Result

-o- FE Result

(e)

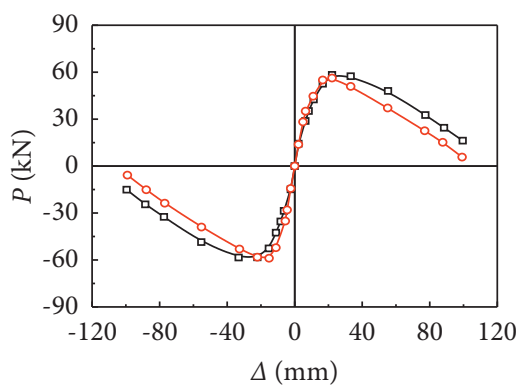

- - Test Result

-०- FE Result

(c)

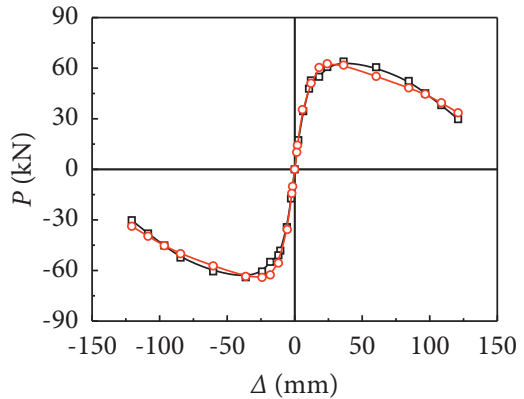

- - Test Result

-॰- FE Result

(f)

Figure 14: Continued. 


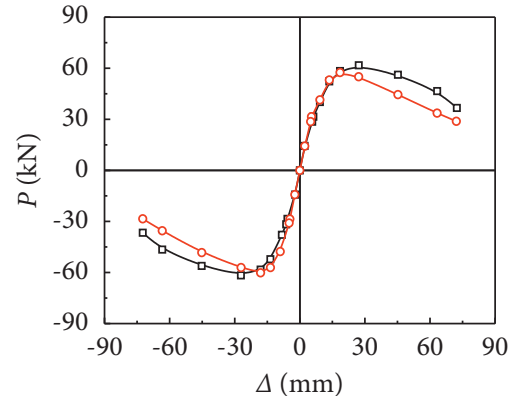

$$
\begin{aligned}
& -\square-\text { Test Result } \\
& -\circ-\text { FE Result }
\end{aligned}
$$

(g)

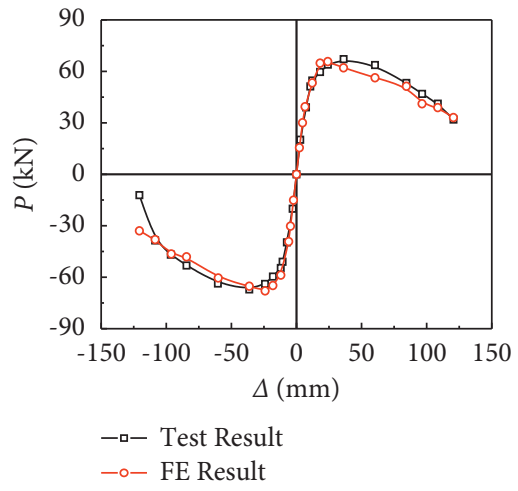

(j)

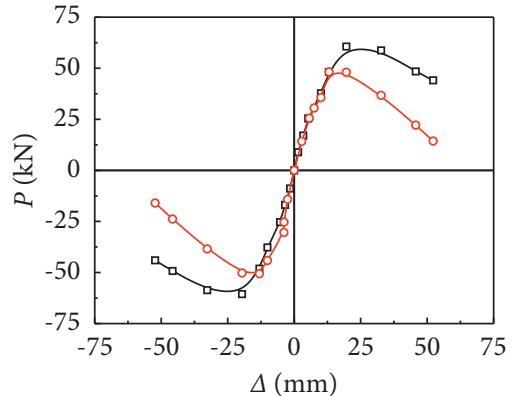

$$
-\square-\text { Test Result }
$$$$
\text { -o- FE Result }
$$

(h)



$-\square-$ Test Result -o- FE Result

(k)

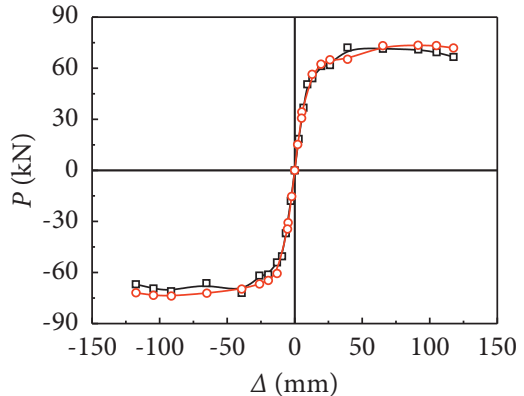

$-\square-$ Test Result -o- FE Result

(i)

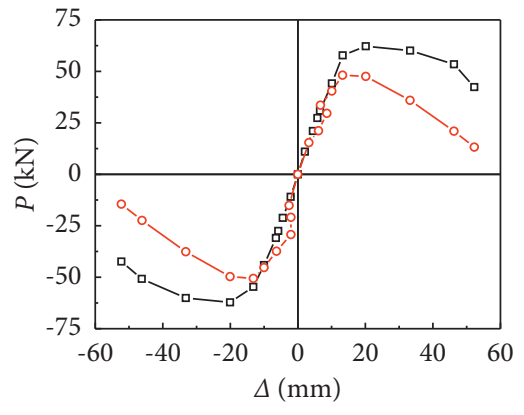

$-\square-$ Test Result

-o- FE Result

(l)

Figure 14: Comparison of simulation results and experimental results of $P-\Delta$ skeleton curves of specimens. (a) A0 specimen. (b) B0 specimen. (c) C0 specimen. (d) D0 specimen. (e) A1 specimen. (f) B1 specimen. (g) C1 specimen. (h) D1 specimen. (i) A2 specimen. (j) B2 specimen. (k) C2 specimen. (l) D2 specimen.

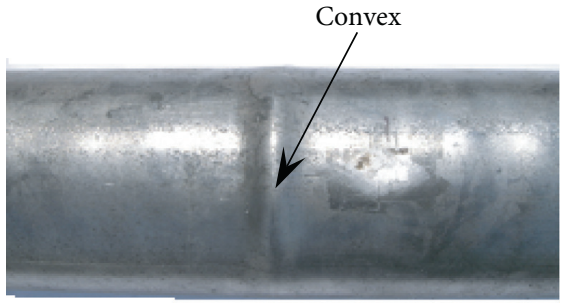

(a)

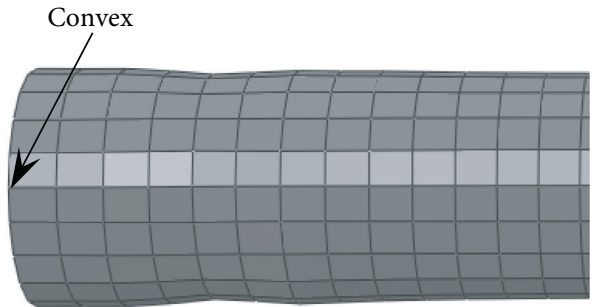

(b)

FIgURe 15: Failure modes of steel tube with middle section. (a) Test result. (b) FE result.

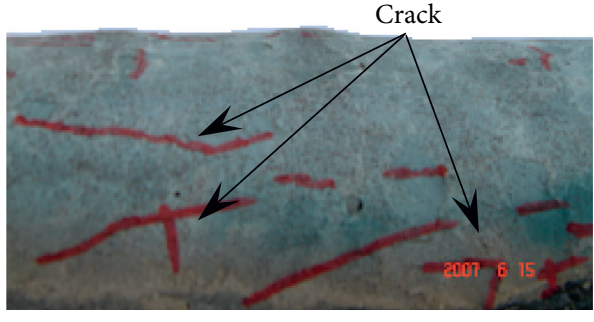

(a)

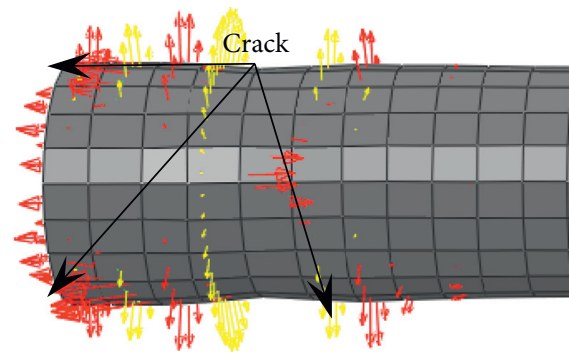

(b)

FIGURE 16: Failure modes of concrete with middle section. (a) Test result. (b) FE result. 
TABLE 5: Comparative error analysis of test and finite element skeleton curves.

\begin{tabular}{|c|c|c|c|c|c|c|}
\hline No. & $\begin{array}{l}\text { Elastic stiffness } \\
\text { of test }(\mathrm{mm} / \\
\mathrm{kN})\end{array}$ & $\begin{array}{l}\text { Elastic stiffness of } \\
\text { FE result }(\mathrm{mm} / \\
\mathrm{kN})\end{array}$ & $\begin{array}{l}\text { The comparative error } \\
\text { of elastic stiffness (\%) }\end{array}$ & $\begin{array}{c}\text { The ultimate } \\
\text { bearing capacity of } \\
\text { test }(\mathrm{kN})\end{array}$ & $\begin{array}{l}\text { The ultimate bearing } \\
\text { capacity of FE result } \\
(\mathrm{kN})\end{array}$ & $\begin{array}{c}\text { The comparative error of } \\
\text { the ultimate bearing } \\
\text { capacity }(\%)\end{array}$ \\
\hline A0 & 6.16 & 5.78 & 93.83 & 72.64 & 71.50 & 98.43 \\
\hline B0 & 5.18 & 4.85 & 93.62 & 60.08 & 61.09 & 98.34 \\
\hline $\mathrm{C} 0$ & 4.53 & 5.07 & 80.50 & 58.26 & 56.24 & 96.53 \\
\hline D0 & 3.67 & 3.48 & 94.82 & 56.47 & 48.52 & 85.92 \\
\hline A1 & 5.18 & 6.22 & 83.27 & 74.9 & 73.88 & 98.63 \\
\hline B1 & 5.41 & 6.12 & 88.39 & 63.92 & 62.60 & 97.93 \\
\hline $\mathrm{C} 1$ & 4.99 & 5.73 & 87.08 & 61.70 & 57.49 & 93.17 \\
\hline D1 & 4.79 & 4.45 & 92.90 & 60.61 & 48.72 & 80.39 \\
\hline A2 & 5.63 & 6.47 & 87.01 & 72.18 & 73.47 & 98.24 \\
\hline $\mathrm{B} 2$ & 5.31 & 5.94 & 89.39 & 67.13 & 65.7 & 97.86 \\
\hline $\mathrm{C} 2$ & 5.28 & 5.50 & 96.00 & 65.52 & 57.48 & 87.72 \\
\hline D2 & 4.73 & 3.95 & 83.50 & 62.21 & 50.14 & 79.38 \\
\hline
\end{tabular}

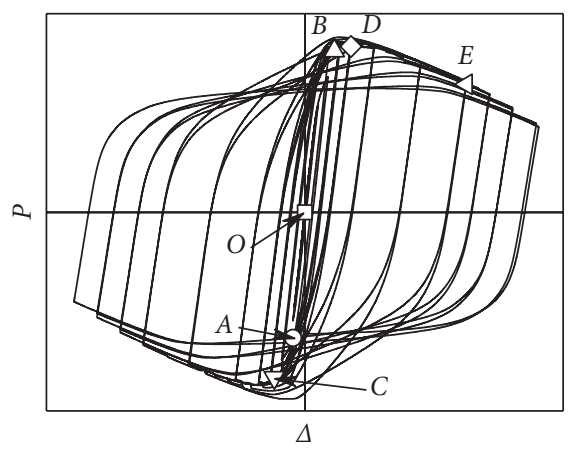

Figure 17: The typical $P$ - $\Delta$ curve of specimens of S-CF-CFRP-ST.

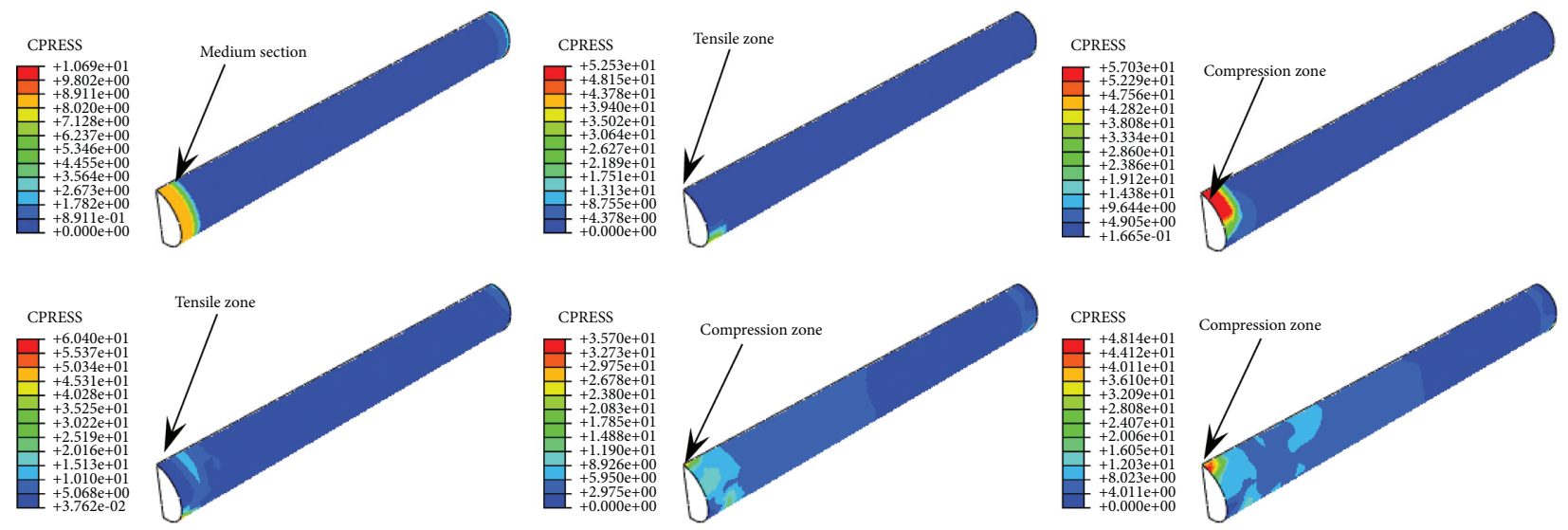

FIGURE 18: Distribution of interaction between steel tube and concrete in members.

range of steel tube reached (point $A$ ), the interaction increases sharply. After the CFRP fracture at points $B$ and $C$, the interaction continues to increase. At point $D$, the load reaches the bearing capacity, and the interaction of member begins to decrease. At point $E$, the interaction of member has been increased again.
5.2. Longitudinal Stress Distribution of Concrete in Tube. Figure 19 shows the longitudinal stress distribution of concrete in the C-CF-CFRP-ST specimens during loading from point $O$ to point $E$. It can be seen that, at point $O$, the concrete was under whole section compression, and the maximum compressive stress of the circular member is 

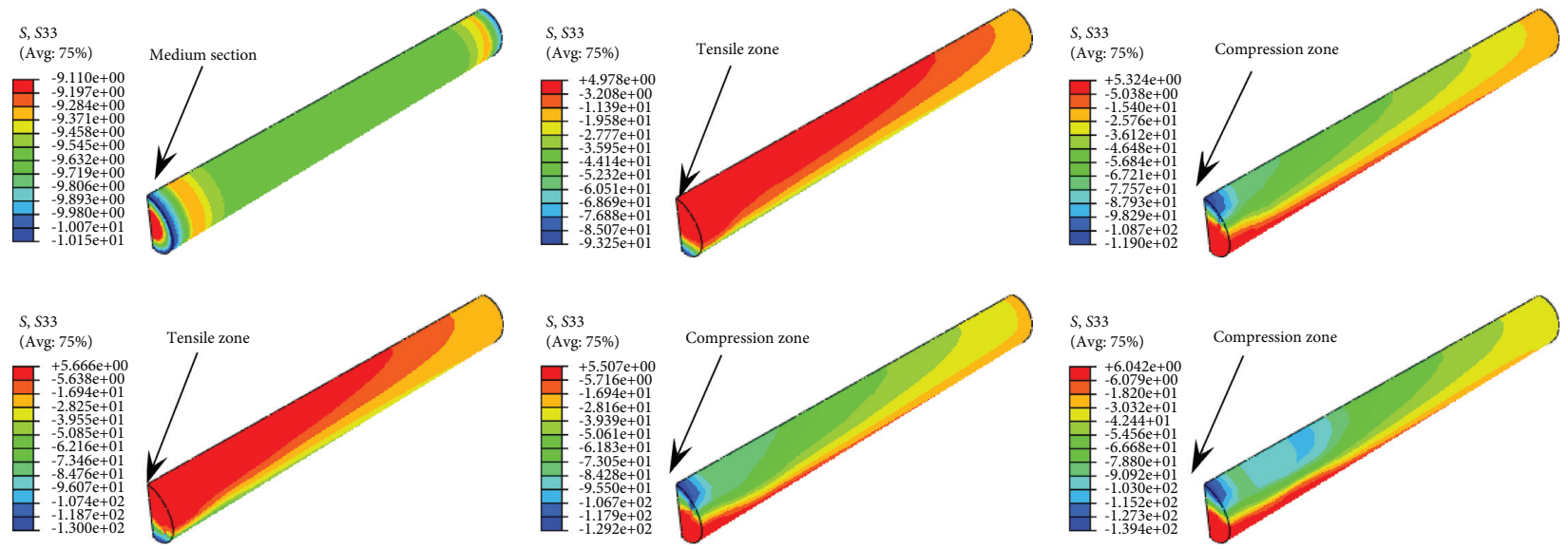

Figure 19: The longitudinal stress distribution of concrete in the specimens.

mainly concentrated in the outermost edge of the concrete. At point $A$, the stress of the concrete increases significantly due to the restraint effect of the steel tube, and the tensile zone begins to appear in the section. At points $B$ and $C$, with the gradual increase of the deflection of the middle section, the maximum compressive stress of the concrete further increases. After that, the stress of the members almost does not increase. The longitudinal stress at point $C$ is consistent with point $D$, and the specimen reaches the maximum compressive stress at point E.

5.3. Stress Distribution of Steel Tube. Figure 20 shows the longitudinal stress distribution of the steel tube in S-CFCFRP-ST specimens during loading from point $O$ to point $E$. It can be seen that the full section of the specimens was compressed at point $O$. The steel tube remained in the elastic stage with a light load at point $O$, and the stress distribution along the length of the specimens was relatively uniform. At point $A$, the steel tube in the tension zone of the middle section of the member enters the yield stage. When loading to points $B$ and $C$, the stress of the steel tube gradually increases, and with the CFRP fracture, the yield region of the steel tube gradually develops to both ends of the member. At points $C$ and $D$, the stress of the steel tube is basically unchanged. In addition, it can be seen that the distribution of longitudinal stress of steel tube is basically consistent with that of concrete.

\subsection{Stress Distribution of Longitudinal CFRP.} Longitudinal CFRP was taken as a variable in the test, so the longitudinal stress distribution was studied. Figure 21 shows the CFRP's longitudinal stress distribution in the C-CFCFRP-ST specimens during loading from point $O$ to point $E$. It can be seen that, at $O$ point, the longitudinal CFRP is almost not stressed, because CFRP only produces tensile stress along the fiber direction. When the yield of steel tube is reached ( $A$ point), the stress in the section in the tensile zone is the largest, and the longitudinal CFRP is still in the elastic stage and does not fracture. With the gradual increase of the deflection of the section, the stress in the section of the tensile zone gradually increases and reaches the fracture strength at point $B$. The results show that the longitudinal CFRP in tension zone delays the deformation. As the failure area of longitudinal CFRP increases, the stress decreases gradually. During the whole loading process, the longitudinal CFRP in the compression zone has no effect.

\section{Restoring Force Model}

The finite element simulation of C-CF-CFRP-ST specimens' $P-\Delta$ curve is complex to use in practice, so it is necessary to propose a simplified restoring force model. Through a large number of calculations on the C-CF-CFRP-ST specimens' $P$ $\Delta$ curves (the stage of each parameter: $n=0 \sim 0.8$, $f_{\mathrm{y}}=235 \sim 420 \mathrm{MPa}, f_{\mathrm{cu}}=30 \sim 90 \mathrm{MPa}, \alpha=0.03 \sim 0.2, \xi_{\mathrm{cf}}=0 \sim 0.6$, $\eta=0 \sim 0.9$, and $\lambda=10 \sim 80$ ), it was found that the specimens' restoring force model can be modified appropriately, and then a model suitable for C-CF-CFRP-ST beam-column was proposed [23, 24].

6.1. Trilinear Model. As shown in Figure 22, the restoring force model for S-CF-CFRP-ST specimens can be used to calculate from one circle at the end of the elastic stage to the end of loading. In Figure 18, point $A$ is the end of the skeleton curve's linear elastic stage, and its lateral loading was taken as 0.6 times the skeleton curve's peak loading $\left(P_{\mathrm{y}}\right)$. The $O A$ segment's stiffness was defined as $K_{\mathrm{a}}$.

Point $B$ is the skeleton line's peak point, and its lateral loading $\left(P_{\mathrm{y}}\right)$ corresponding to the displacement was $\Delta_{\mathrm{p}}$. The stiffness along the $B C$ segment was defined as $K_{\mathrm{T}}$. When unloading from point 1 or 4 in Figure 18, the unloading was performed according to the stiffness of the elastic stage $\left(K_{\mathrm{a}}\right)$ and was loaded to point 2 or 5 . The loading value of point 2 was taken as $(0.2+n)$ times the loading value of point 1 in the ordinate, and the loading value of point 4 in the ordinate was taken as $(0.2+1.2 n)$ times the loading value of point 5 in the ordinate. As the reverse loading continued to increase, the model entered the softening segment of $23^{\prime}$ or $5 \mathrm{D}^{\prime}$. Points $3^{\prime}$ and $D^{\prime}$ were on the extension line of $\mathrm{OA}$, and their ordinates were the same as points 1 (or 3) and 4 (or D), respectively. Finally, the loading path was carried out along 
S, $S 22$

SNEG, (fraction $=-1.0$ )

(Avg: $75 \%$ )

$\square \begin{array}{r}-4.326 \mathrm{e}+00 \\ -1.124 \mathrm{e}+01\end{array}$

$-1.816 \mathrm{e}+01$
$-2.507 \mathrm{e}+01$

$-2.507 e+01$
$-3.199 e+01$
$-3.59 e+01$

$-3.890 \mathrm{e}+01$

$-4.582 \mathrm{e}+01$

$-5.274 \mathrm{e}+01$

$-5.965 e+01$
$-6.657 e+01$

$-7.348 \mathrm{e}+01$

$-8.040 e+01$
$-8.731 e+01$

S, $S 22$

SNEG, (fraction $=-1.0)$

(Avg: 75\%)

$\nabla_{+}^{+3.069 \mathrm{e}+02}+2.606 \mathrm{e}+02$

$+2.606 \mathrm{e}+02$
$+2.144 \mathrm{e}+02$
+

$+1.682 \mathrm{e}+02$

$+1.219 \mathrm{e}+02$

$+7.568 \mathrm{e}+01$
$+2.943 \mathrm{e}+01$
$-1.6810+01$

$-1.681 \mathrm{e}+01$

$-6.305 e+01$

$-1.093 e+02$
$-1.555 e+02$

$-2.018 \mathrm{e}+02$

$2.480 \mathrm{e}+02$

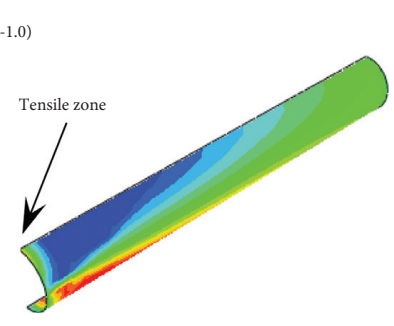

S, S22

SNEG, (fraction $=-1.0$ )

(Avg: 75\%)

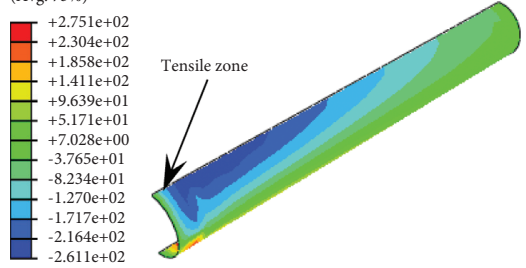

$S, S 22$

SNEG, (fraction $=-1.0$ )

(Avg: 75\%)

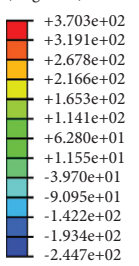

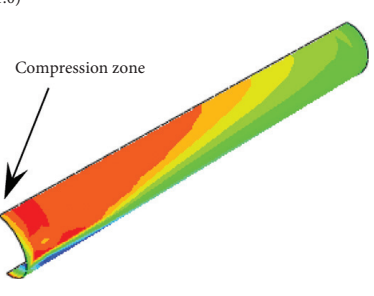

S, $S 22$

SNEG, (fraction $=-1.0$ ) (Avg: 75\%)

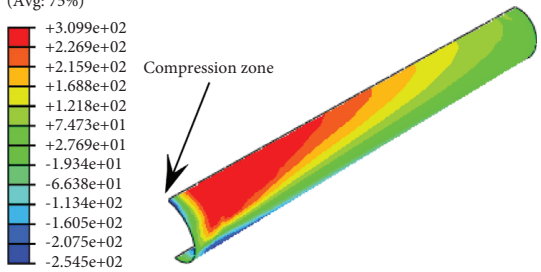

S, $S 22$

SNEG, (fraction $=-1.0$ )

(Avg: 75\%)
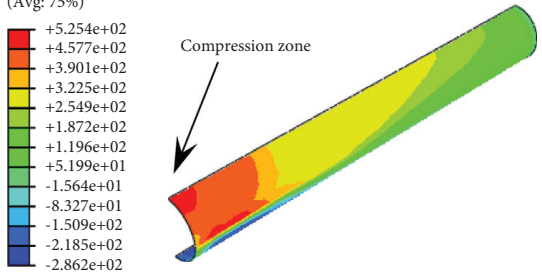

Figure 20: The longitudinal stress distribution of the steel tube in specimens.
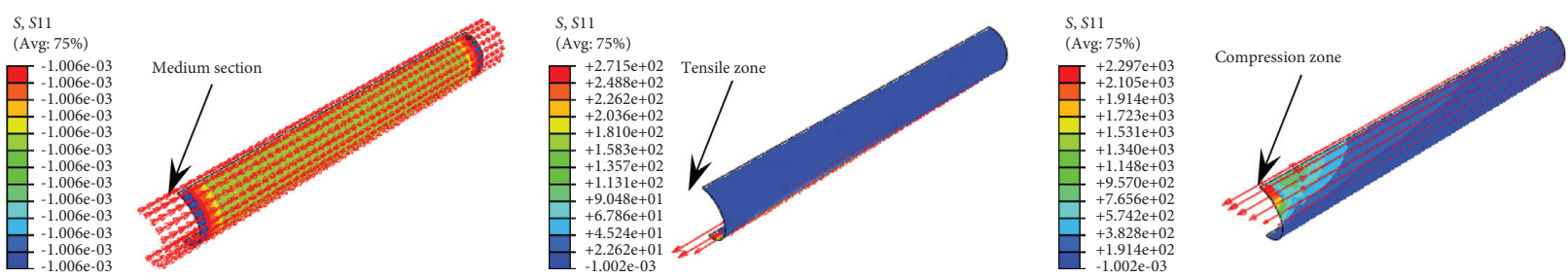

S, S11
(Avg: $75 \%)$
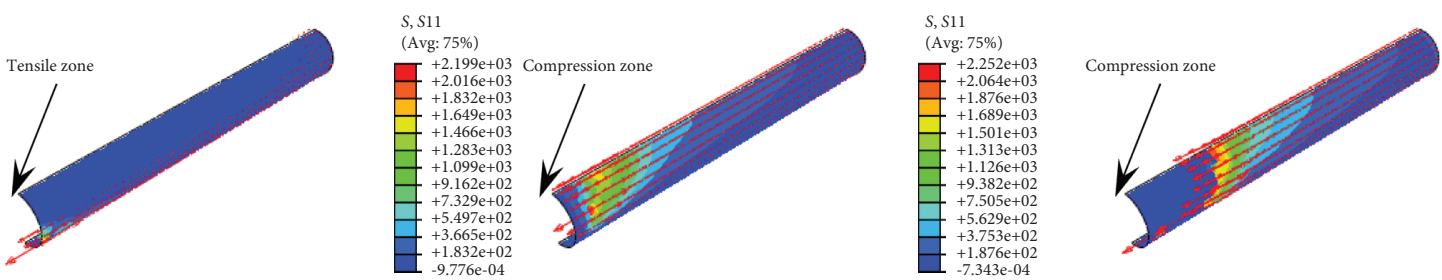

FIgURE 21: The CFRP's longitudinal stress distribution in the specimens.

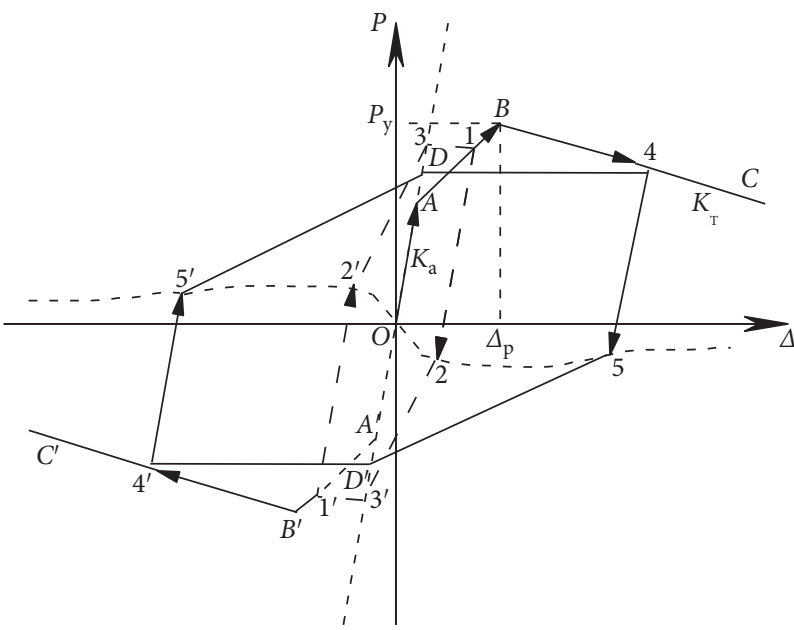

FIGURE 22: Restoring force model of S-CF-CFRP-ST specimens. 
$3^{\prime} 1^{\prime} 2^{\prime} 3$ or $D^{\prime} 4^{\prime} 5^{\prime} D$, and the method to determine the softening segment $2^{\prime} 3$ and $5^{\prime} D$ is similar to that of $23^{\prime}$ and $5 D^{\prime}$, respectively.

It can be seen that if the displacement $\left(\Delta_{\mathrm{p}}\right)$ and the lateral loading $\left(P_{\mathrm{y}}\right)$ at point $B$ and the stiffness $\left(K_{\mathrm{a}}\right)$ in the elastic stage and the stiffness $\left(K_{\mathrm{T}}\right)$ of the third segment are determined, the restoring force model can be calculated according to the process above.

\subsection{Determination of Trilinear Model}

6.2.1. Determination of $\mathrm{Ka}$. According to the results of the parametric analysis, the stiffness $\left(K_{\mathrm{a}}\right)$ of the S-CF-CFRP-ST specimens' restoring force model is shown as follows:

$$
\begin{aligned}
K_{a} & =\frac{3 K_{e}}{L_{1}^{3}}, \\
K_{e} & =E_{s} I_{s}+0.2 E_{c} I_{c}+5 E_{\mathrm{cf}} I_{\mathrm{cfl}}, \\
L_{1} & =\frac{L}{2} .
\end{aligned}
$$

which $I_{\mathrm{s}}, I_{\mathrm{c}}$, and $I_{\mathrm{cfl}}$ are the section inertia of the steel tube, concrete, and longitudinal CFRP, respectively.

6.2.2. Determination of $\Delta_{p}$ and $P_{y}$. The results show that the specific expression of component $\Delta_{\mathrm{p}}$ is as follows:

$$
\begin{aligned}
\Delta_{P} & =\frac{6.74\left[(\ln r)^{2}-1.08 \ln r+3.33\right]\left(0.8-n \xi_{\mathrm{cf}}\right)(0.8-0.7 n \eta) f_{1}(n) \frac{P_{y}}{K_{a}},}{8.7-s} \\
f_{1}(n) & = \begin{cases}1.336 n^{2}-0.044 n+0.804, & 0 \leq n \leq 0.5, \\
1.126-0.02 n, & 0.5<n<1 .\end{cases}
\end{aligned}
$$

where $r=\lambda / 40$ and $s=f_{\mathrm{y}} / 345$.

The results show that the specific expression of component $P_{\mathrm{y}}$ is as follows:

$$
\begin{aligned}
& P_{\mathrm{y}}= \begin{cases}1.05 a f_{1}\left(\xi_{\mathrm{cf}}, \eta, n\right) \frac{M_{\mathrm{y}}}{L_{1}}, & 1<\xi \leq 4, \\
(0.2 \xi+0.85) a f_{1}\left(\xi_{\mathrm{cf}}, \eta, n\right) \frac{M_{\mathrm{y}}}{L_{1}}, & 0.2 \leq \xi \leq 1,\end{cases} \\
& a= \begin{cases}0.96-0.002 \xi, & 0 \leq n \leq 0.3, \\
(1.4-0.34 \xi) n+0.1 \xi+0.54, & 0.3<n<1 .\end{cases}
\end{aligned}
$$

The expression of $f_{1}\left(\xi_{\mathrm{cf}}, \eta, n\right)$ is obtained by regression of a large number of calculation results.

$$
\begin{aligned}
f_{1}\left(\xi_{\mathrm{cf}}, \eta, n\right) \\
\quad= \begin{cases}1.4-5.7\left(0.35-20 \xi_{\mathrm{cf}} n\right)(n-0.3)+0.1(1+\eta)^{2+n}, & \xi_{\mathrm{cf}} \leq 0.1, \\
1.34-2.37\left(1-3 \xi_{\mathrm{cf}}\right)(n-0.35)-0.01 \eta^{1+n}, & \xi_{\mathrm{cf}}>0.1 .\end{cases}
\end{aligned}
$$

The results show that the specific expression of component $M_{\mathrm{y}}$ of specimens is as follows:

$$
\begin{aligned}
M_{y} & =\frac{A_{1} c+B_{1}}{\left(A_{1}+B_{1}\right)(p n+q)} f_{2}\left(\xi_{\mathrm{cf}}, \eta, n\right) M_{\mathrm{bc}}, \\
A_{1} & = \begin{cases}-0.137, & b \leq 1, \\
0.118 b-0.255, & b>1,\end{cases} \\
B_{1} & = \begin{cases}-0.468 b^{2}+0.8 b+0.874, & b \leq 1, \\
1.306-0.1 b, & b>1,\end{cases}
\end{aligned}
$$

$$
\begin{aligned}
& p= \begin{cases}0.566-0.789 b, & b \leq 1, \\
-0.11 b-0.113, & b>1,\end{cases} \\
& q= \begin{cases}1.195-0.34 b, & b \leq 1, \\
1.025, & b>1,\end{cases} \\
& b=\frac{\alpha}{0.1} .
\end{aligned}
$$

The expression of $f_{2}\left(\xi_{\mathrm{cf}}, \eta, n\right)$ is obtained by using formulas (1) and (20):

$$
f_{2}\left(\xi_{\mathrm{cf}}, \eta, n\right)=1-1.5 \xi_{\mathrm{cf}} n-\eta^{0.1(1+n)} .
$$

6.2.3. Determination of $K_{T}$. The stiffness $\left(K_{\mathrm{T}}\right)$ of the specimens' third segment is as follows:

$$
\begin{aligned}
& K_{T}= \frac{\left[0.03 f_{2}(n) f(r, \alpha) K_{a}\right]}{\left(c^{2}-3.39 c+5.41\right)}, \\
& f_{2}(n)= \begin{cases}3.043 n-0.21, & 0 \leq n \leq 0.7, \\
0.5 n+1.57, & 0.7<n<1,\end{cases} \\
& f(r, a)= \begin{cases}{\left[8 \alpha\left(1+5 \xi_{\mathrm{cf}}\right)(1+\eta)-8.6\right] r+6 \alpha+0.9,} & r \leq 1, \\
{\left[15 \alpha\left(1-0.02 \xi_{\mathrm{cf}}\right)(1-2 \eta)-13.8\right] r+6.1-\alpha,} & r>1,\end{cases}
\end{aligned}
$$

where $c=f_{\mathrm{cu}} / 60$.

6.3. Comparison of Restoring Force Model Results and Finite Element Simulation Results. Figure 23 shows the comparison between the restoring force model's results and the finite element simulation results in the C-CF-CFRP-ST specimens' $P-\Delta$ curve. It can be seen that the restoring force model 


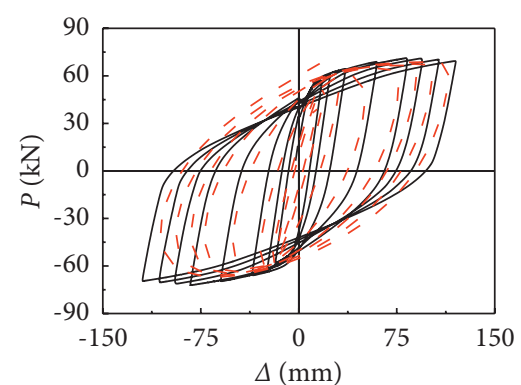

_ FE result

-- Calculation result

(a)

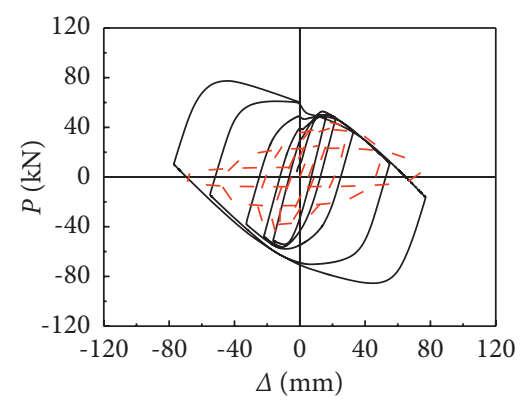

— FE results

- - Calculation result

(d)

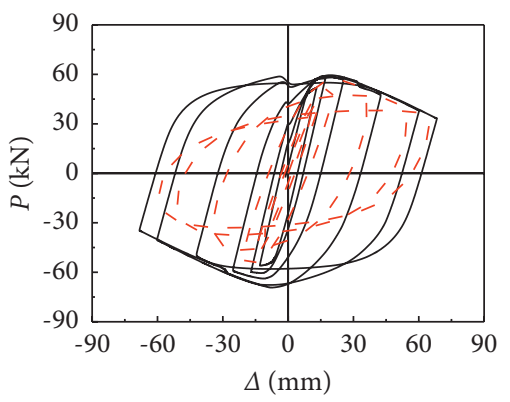

- FE result

- - - Calculation result

(g)

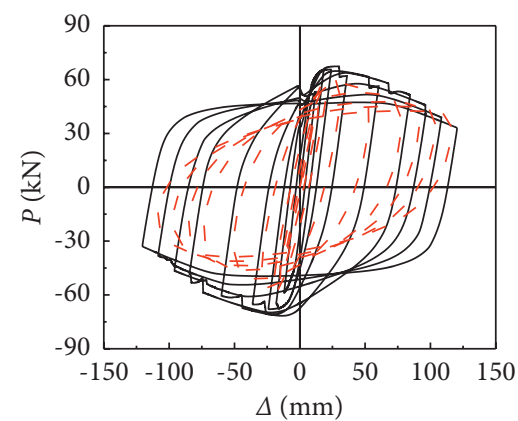

— FE results

- - Calculation result

(j)

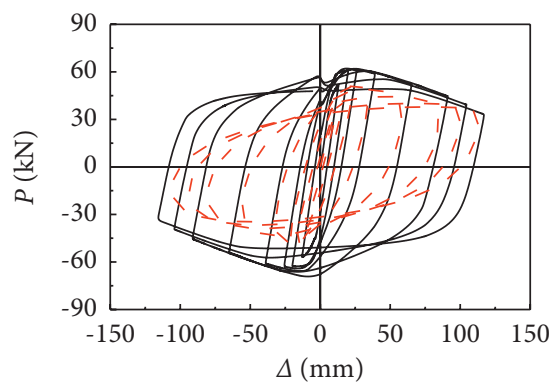

_ FE results

- . Calculation result

(b)

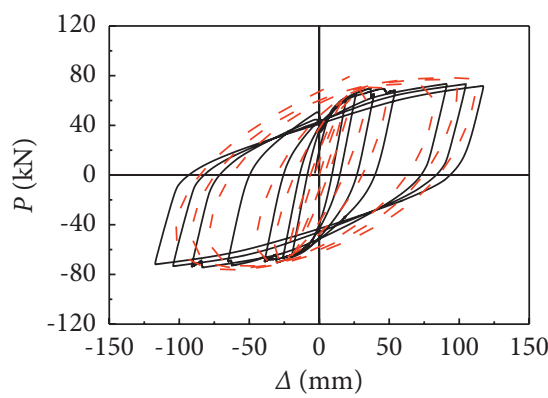

_ FE results

- - - Calculation result

(e)

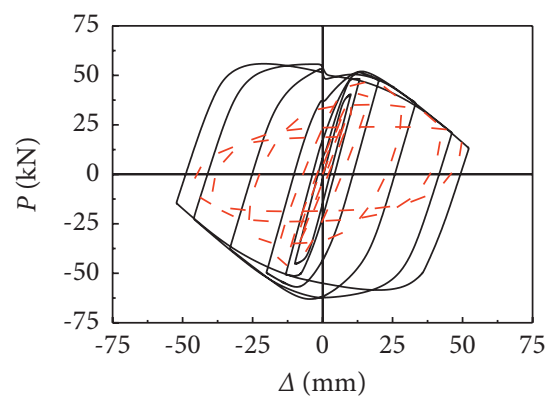

- FE result

- - Calculation result

(h)

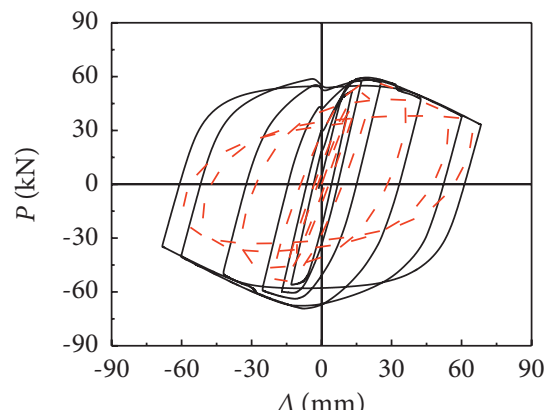

— FE results

- - - Calculation result

(k)

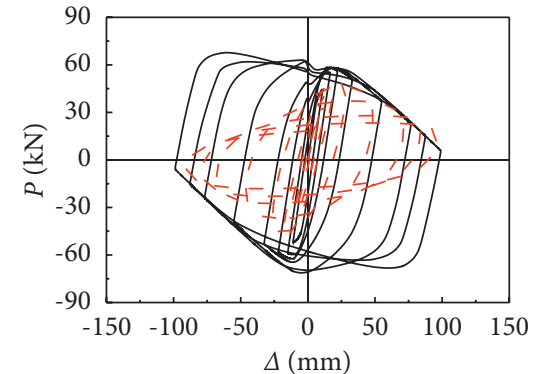

_ FE results

- - Calculation result

(c)

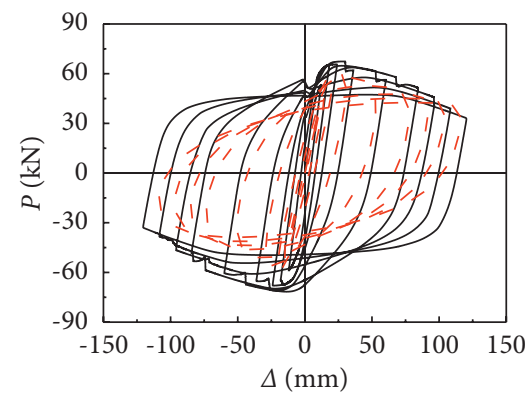

— FE result

- - Calculation result

(f)

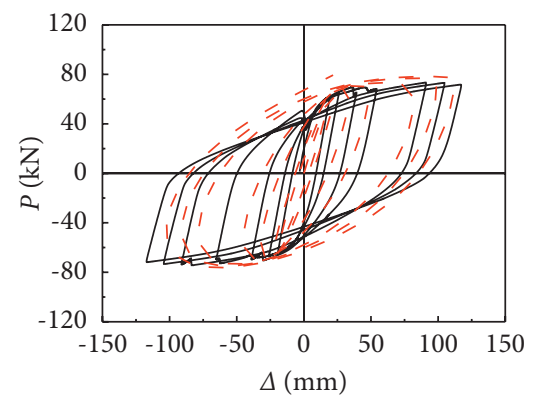

- FE results

- - - Calculation result

(i)

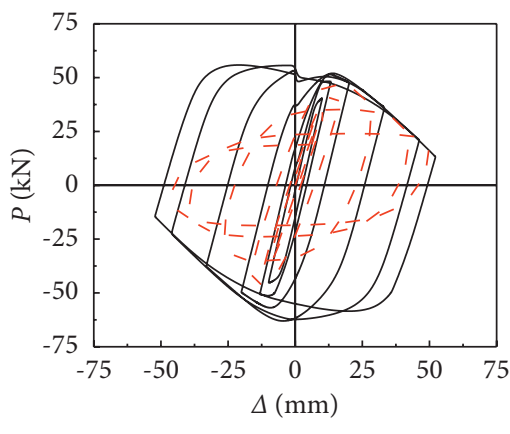

— FE results

- - - Calculation result

(l)

FIgURE 23: The comparison between the restoring force model's results and the finite element simulation results. (a) A0 specimen. (b) B0 specimen. (c) C0 specimen. (d) D0 specimen. (e) A1 specimen. (f) B1 specimen. (g) C1 specimen. (h) D1 specimen. (i) A2 specimen. (j) B2 specimen. (k) C2 specimen. (l) D2 specimen. 

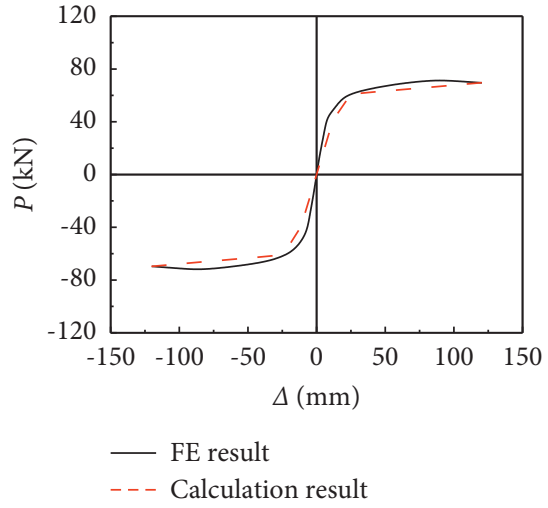

(a)

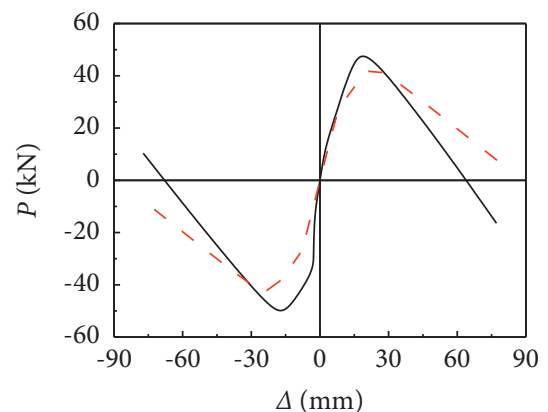

— FE result

- - - Calculation result

(d)

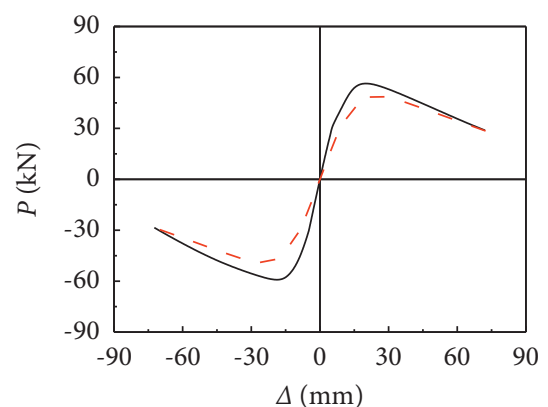

— FE result

- - - Calculation result

(g)

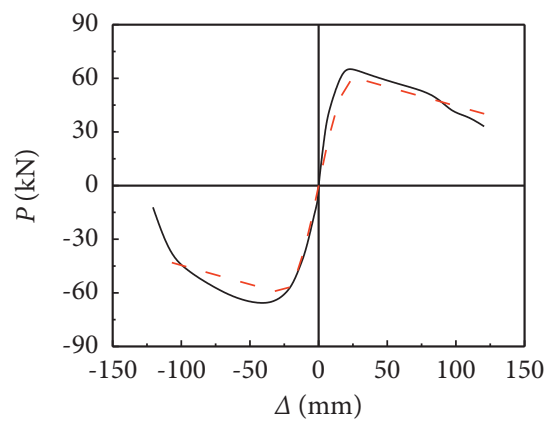

- FE result

- - - Calculation result

(j)

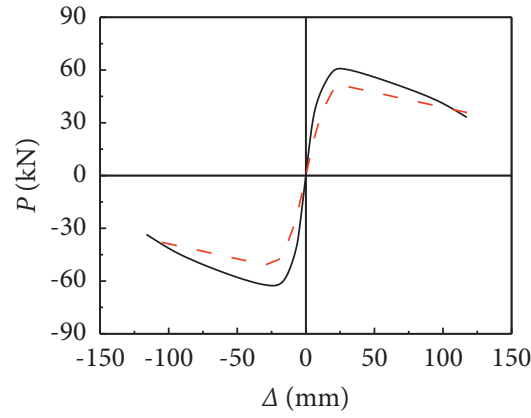

— FE result

- - - Calculation result

(b)

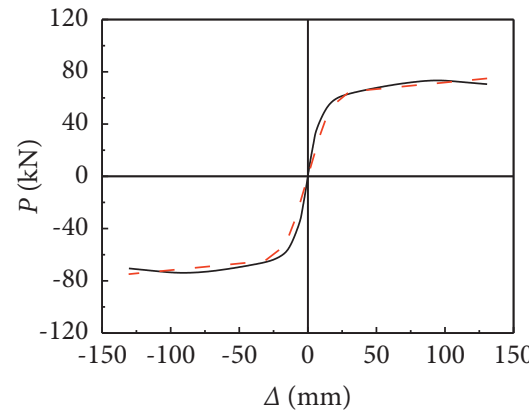

— FE result

- - - Calculation result

(e)

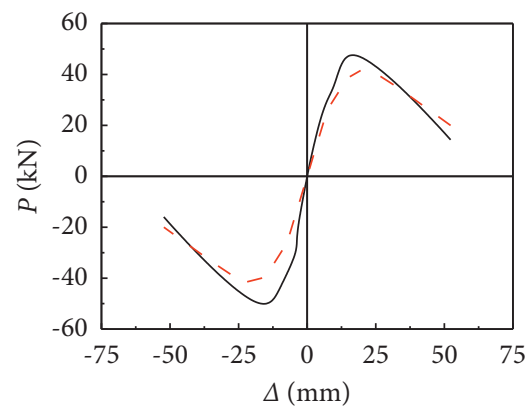

- FE result

- - - Calculation result

(h)

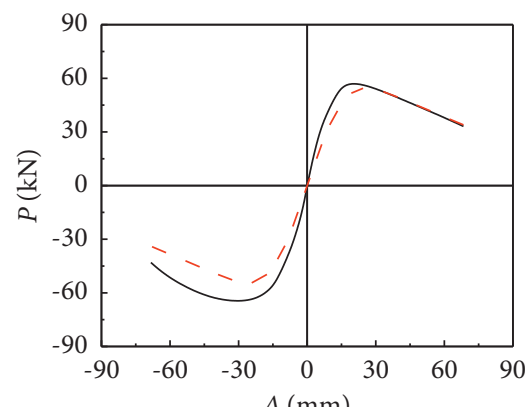

- FE result

- - - Calculation result

(k)

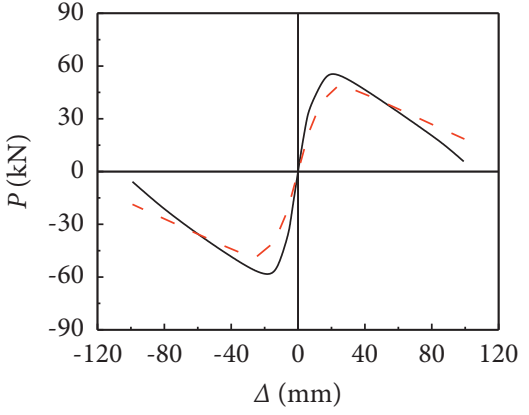

- FE result

- - - Calculation result

(c)

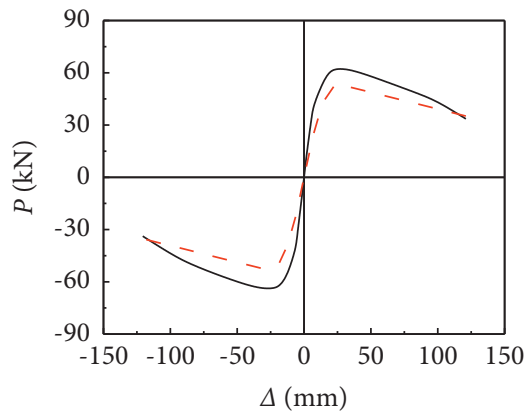

— FE result

- - - Calculation result

(f)

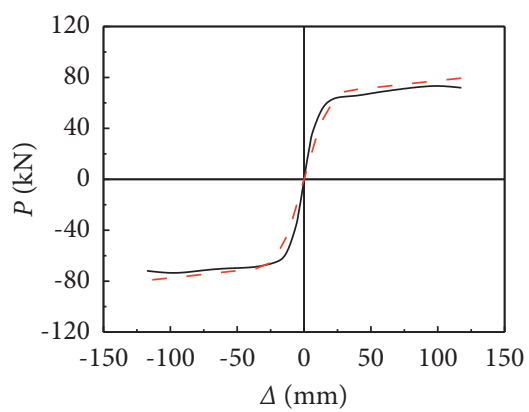

— FE result

- - - Calculation result

(i)

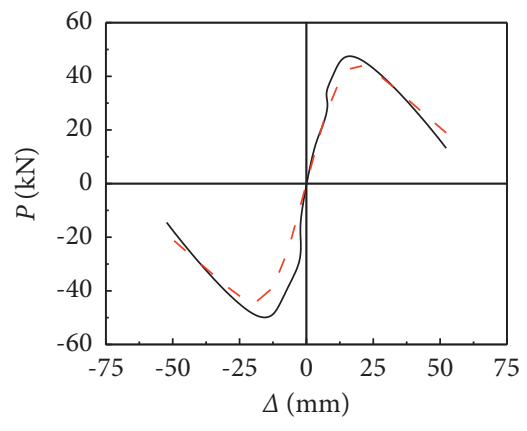

— FE result

- - Calculation result

(1)

Figure 24: The comparison between the restoring force model's results and the finite element simulation results of skeleton curve. (a) A0 specimen. (b) B0 specimen. (c) C0 specimen. (d) D0 specimen. (e) A1 specimen. (f) B1 specimen. (g) C1 specimen. (h) D1 specimen. (i) A2 specimen. (j) B2 specimen. (k) C2 specimen. (l) D2 specimen. 
TABLE 6: Comparative error analysis of calculation and finite element skeleton curves.

\begin{tabular}{|c|c|c|c|c|c|c|}
\hline No. & $\begin{array}{c}\text { Elastic stiffness of } \\
\text { calculation result } \\
(\mathrm{mm} / \mathrm{kN})\end{array}$ & $\begin{array}{c}\text { Elastic stiffness } \\
\text { of FE result } \\
(\mathrm{mm} / \mathrm{kN})\end{array}$ & $\begin{array}{l}\text { The comparative } \\
\text { error of elastic } \\
\text { stiffness }(\%)\end{array}$ & $\begin{array}{c}\text { The ultimate bearing } \\
\text { capacity of calculation } \\
\text { result }(\mathrm{kN})\end{array}$ & $\begin{array}{l}\text { The ultimate } \\
\text { bearing capacity of } \\
\text { FE result }(\mathrm{kN})\end{array}$ & $\begin{array}{c}\text { The comparative error of } \\
\text { the ultimate bearing } \\
\text { capacity }(\%)\end{array}$ \\
\hline A0 & 5.32 & 5.78 & 92.64 & 69.63 & 71.50 & 97.38 \\
\hline B0 & 3.97 & 4.85 & 78.16 & 51.4 & 61.09 & 84.13 \\
\hline $\mathrm{C} 0$ & 4.66 & 5.77 & 80.76 & 49.64 & 56.24 & 88.26 \\
\hline D0 & 3.47 & 3.48 & 99.28 & 44.48 & 48.52 & 91.67 \\
\hline $\mathrm{A} 1$ & 5.73 & 6.22 & 92.12 & 73.55 & 73.88 & 99.55 \\
\hline B1 & 4.67 & 6.12 & 76.20 & 53.74 & 62.60 & 85.84 \\
\hline $\mathrm{C} 1$ & 4.51 & 5.73 & 76.42 & 50.39 & 57.49 & 87.65 \\
\hline D1 & 3.77 & 4.45 & 82.03 & 44.56 & 48.72 & 91.45 \\
\hline A2 & 5.18 & 6.47 & 80.06 & 78.00 & 73.47 & 94.16 \\
\hline B2 & 4.39 & 5.94 & 73.90 & 60.7 & 965.7 & 92.38 \\
\hline $\mathrm{C} 2$ & 4.75 & 5.50 & 86.36 & 57.26 & 57.48 & 99.61 \\
\hline D2 & 3.64 & 3.95 & 92.51 & 46.73 & 48.14 & 97.07 \\
\hline
\end{tabular}

results agreed well with those of the finite element simulation.

Figure 24 shows the comparison between the restoring force model's results and the finite element simulation results of skeleton curve. It can be seen that the restoring force model results agreed well with those of the finite element simulation. Table 6 shows comparative error analysis of calculation and finite element skeleton curves. The calculation results show that the error between test and finite element is less than $25 \%$. The calculation results show that the error between test and finite element is less than $20 \%$. The mean square deviation of elastic stiffness and ultimate bearing capacity between restoring force model and finite element is calculated. The mean square deviation of elastic stiffness between restoring force model and finite element is 0.81 , and the mean square deviation of the ultimate bearing capacity between restoring force model and finite element is 0.93. This shows that the finite element model is in good agreement with the restoring force model results.

\section{Conclusion}

(1) CFRP have a good transverse restraint and longitudinal reinforcement effect on CFST, and the steel tube's local buckling is delayed. The specimens' bearing capacity improved with the increase in the axial compression ratio and longitudinal CFRP reinforcement coefficient.

(2) The typical $P-\Delta$ hysteretic curves of members are established by ABAQUS, and the simulation results are in good agreement with the experimental results. Combined with this model, the stress distribution of each component material is analyzed, which reflects that the longitudinal stress distribution of concrete and steel tube is consistent, and the stress increases gradually from both ends to the middle section. The maximum stress of each group of specimens appears at the outermost edge of the middle section of the specimens.

(3) Based upon the trilinear model, the restoring force model of S-CF-CFRP-ST was built, and the results of the model agreed well with those of the finite element simulation.

\section{Data Availability}

The data generated or analyzed during this study are included within this article.

\section{Conflicts of Interest}

The authors declare that they have no conflicts of interest.

\section{Acknowledgments}

The research reported in the study was supported by Project for Talent of Liaoning Province (no. XLYC1902009) and PH.D. Startup Fund of Natural Science Foundation of Liaoning Province, China (20170520139).

\section{References}

[1] Y. Liu and Z. Dong, "Experimental study on torsional behavior of circular CFRP concrete filled steel tube," Journal of Civil Engineering, vol. 42, no. 11, pp. 91-101, 2009, in Chinese.

[2] M. L. Romero and A Espinos, F. Lapuebla, V. Albero, and A. Hospitaler, Recent developments and fire design provisions for CFST columns and slim-floor beams," Journal of Constructional Steel Research, vol. 172, no. 1-21, 2020.

[3] L. H. Han and S. T. Zhong, "Bearing capacity correlation equations of concrete filled steel tubular members under compression torsion and bending torsion," Journal of Harbin Institute of architectural engineering, vol. 27, no. 2, pp. 32-37, 2004, in Chinese.

[4] J. G. Nie, Y. H. Wang, and J. S. Fan, "Study on seismic behavior of concrete filled steel tube under pure torsion and compression torsion load," Ocean Engineering, vol. 47, no. 1, pp. 47-58, 2014.

[5] X. H. Zhou, Y. H. Wang, and G. B. Lu, "Research on mechanical behavior of hollow sandwich concrete filled steel tubular columns under reciprocating pure torsion," Journal of building structure, vol. 38, no. S1, pp. 266-271, 2017.

[6] J. G. Nie, Y. H. Wang, and J. S. Fan, "Study on seismic behavior of concrete filled steel tubular columns under pure 
torsion and compression torsion load," Steel and Composite Structures, vol. 47, no. 1, pp. 47-58, 2014.

[7] J. Nie, C. S. Cai, and T. Wang, "Stiffness and capacity of steelconcrete composite beams with profiled sheeting," Engineering Structures, vol. 27, no. 7, pp. 1074-1085, 2005.

[8] Y. K. Hong and S. M. Choi, "Behaviors of concrete filled square steel tubes confined by carbon fiber sheets (CFS) under compression and cyclic loads," Steel and Composite Structures, vol. 10, no. 2, pp. 187-205, 2010.

[9] M. C. Sundarraja and G. G. Prabhu, "Investigation on strengthening of CFST members under compression using CFRP composites," Journal of Reinforced Plastics and Composites, vol. 30, no. 15, pp. 1251-1264, 2011.

[10] Z. Tao, L.-H. Han, and J.-P. Zhuang, "Axial loading behavior of CFRP strengthened concrete-filled steel tubular stub columns," Advances in Structural Engineering, vol. 10, no. 1, pp. 37-46, 2007.

[11] Z. Tao, L.-H. Han, and L.-L. Wang, "Compressive and flexural behaviour of CFRP-repaired concrete-filled steel tubes after exposure to fire," Journal of Constructional Steel Research, vol. 63, no. 8, pp. 1116-1126, 2007.

[12] F. L. Peng, Z. Tao, and Z. W Cheng, "Behavior of concretefilled steel tube columns subjected to axial compression," Advances in Materials Science and Engineering, vol. 2018, Article ID 4059675, 153 pages, 2018.

[13] Q.-L. Wang, J. Li, Y.-B. Shao, and W.-J. Zhao, "Flexural performances of square concrete filled CFRP-steel tubes (SCF-CFRP-ST)," Advances in Structural Engineering, vol. 18, no. 8, pp. 1319-1344, 2015.

[14] Y. Che, Q. L. Wang, and Y. B. Shao, "Compressive performances of the concrete filled circular CFRP-steel tube (CCFRP-CFST)," Advanced Steel Construction, vol. 8, no. 4, pp. 311-338, 2012.

[15] L.-H. Han, W. Li, and R. Bjorhovde, "Developments and advanced applications of concrete-filled steel tubular (CFST) structures: members," Journal of Constructional Steel Research, vol. 100, no. 3, pp. 211-228, 2014.

[16] L. H. Han, Z. Tao, and W. Liu, "Concrete filled steel tubular structure-theory and practice," Journal of Fuzhou University, vol. 2001, no. 6, 34 pages, 2001, in Chinese.

[17] Q. Y. Qiao, X. Y. Li, and W. L. Cao, "Study on seismic behavior of complex cross-section multi-cell CFST bifurcatedcolumns," Earthquake Engineering \& Engineering Dynamics, vol. 1, no. 2, pp. 1-8, 2016.

[18] Z. Tao, Z.-B. Wang, L.-H. Han, and B. Uy, "Fire performance of concrete-filled steel tubular columns strengthened by CFRP," Steel and Composite Structures, vol. 11, no. 4, pp. 307-324, 2011.

[19] Q.-L. Wang, Z. Zhao, Y.-B. Shao, and Q.-L. Li, "Static behavior of axially compressed square concrete filled CFRP-steel tubular (S-CF-CFRP-ST) columns with moderate slenderness," Thin-Walled Structures, vol. 110, no. 1, pp. 106-122, 2017.

[20] Z.-B. Wang, Z. Tao, and Q. Yu, "Axial compressive behaviour of concrete-filled double-tube stub columns with stiffeners," Thin-Walled Structures, vol. 120, no. 11, pp. 91-104, 2017.

[21] J. Moon, C. W. Roeder, D. E. Lehman, and H.-E. Lee, “Analytical modeling of bending of circular concrete-filled steel tubes," Engineering Structures, vol. 42, pp. 349-361, 2012.

[22] Z. Ou, B. Chen, K. H. Hsieh, M. W. Halling, and P. J. Barr, "Experimental and analytical investigation of concrete filled steel tubular columns," Journal of Structural Engineering, vol. 137, no. 6, pp. 635-645, 2011.
[23] H. H. Yuan and Yu Tang, "Quasi-static research on seismic performance of steel bridge piers with thin-wall ribbed circular cross section," Steel and Composite Structures, vol. 44, no. 4, pp. 459-464, 2016.

[24] W. Q. Zhu, "Fire Performance of steel reinforced concrete columns," Journal of Structural Engineering, vol. 141, no. 4, pp. 191-204, 2015. 